\title{
A Hesitant Fuzzy Linguistic Multicriteria Decision-Making Method with Interactive Criteria and Its Application to Renewable Energy Projects Selection
}

\author{
Jichang Xiao, Jianfeng Cai, and Xiaodong Wang \\ School of Management, Northwestern Polytechnical University, Xian 710072, China \\ Correspondence should be addressed to Jianfeng Cai; caijf@nwpu.edu.cn
}

Received 27 March 2017; Revised 10 October 2017; Accepted 31 October 2017; Published 12 December 2017

Academic Editor: Ching-Ter Chang

Copyright (c) 2017 Jichang Xiao et al. This is an open access article distributed under the Creative Commons Attribution License, which permits unrestricted use, distribution, and reproduction in any medium, provided the original work is properly cited.

\begin{abstract}
A variety of multicriteria decision-making (MCDM) methods for renewable energy projects evaluation have been proposed, of which the premise of using these methods is to assume that the criteria are independent of each other. However, it may be difficult or costly to build independent criteria set in some cases because renewable energy planning is to pursue a balance of economic, social, and environmental goals, which makes the existence of interaction among criteria be of great possibility. In this paper, we consider a highly ambiguous decision situation, where the experts are allowed to give the evaluations in the form of hesitant fuzzy linguistic terms set (HFLTS). We build a hesitant fuzzy linguistic decision-making model handling the interaction among criteria from the perspective of distance measure and apply it to renewable energy projects selection. The proposed method can consider more fuzzy factors and deal with the interaction among criteria more approximately. It can reduce the decision pressure and improve the decision-making efficiency because the decision makers are allowed to express their preference in form of HFLTS and a decision criteria set of which the criteria are independent of each other is not necessary.
\end{abstract}

\section{Introduction}

Energy is the foundation for development of social and economic. In recent decades, with the completion of industrialization, more and more countries have begun to pay attention to environmental issues and the development of renewable energy, which has been promoted to be the national strategy in some countries. Renewable energy planning is an important part of the development of renewable energy and decision-making for renewable energy projects selection is a complex problem with multiple criteria. Renewable energy projects selection is a typical multi-criteria decisionmaking problem, and the classical MCDM techniques, such as TOPSIS, PROMETHEE and ELECTRE, AHP, grey relation method, weighted sum, and fuzzy set-based methodology, have been successfully used in this field [1-6]. Recently, several influential fuzzy MCDM methods for renewable energy projects evaluation and selection considering the uncertain factors and the fuzzy recognition of human thinking have been proposed [7-18]. Some relevant literature reviews have been done [19-24]. From the existing literature, it can be seen that there is a trend on the research of renewable energy projects selection: more and more uncertain and fuzzy factors took into consideration the decision-making process. Scholars and managers are pursuing high-quality decisionmaking to meet the needs of production and life in the field of renewable energy. What is more, to develop renewable energy is to pursue a balance of economic and social activities and environment. From the reviewed literatures, we find that the renewable energy projects selection problem is a multicriteria decision-making problem considering all the technical, economic, social, and environmental factors, of which the existence of interaction among criteria is of great possibility.

Although a variety of MCDM method for renewable energy projects selection have been proposed, of which the premise of using these methods is to assume that the criteria of the criteria set are independent of each other. However, it may be difficult or costly to build criteria set in which all criteria are independent in some situations. So, in this paper, 
we intend to propose a method considering the interaction among criteria in hesitant fuzzy linguistic context which can handle more fuzzy and uncertain information.

In some situations in real life, due to the high uncertainty of the situation and the limited cognition of human thinking, it is difficult for decision makers to make a choice to select only one alternative from a candidate alternative set or an evaluation arguments set to represent their preference. They may hesitate among several alternatives or evaluation arguments with high hesitation. For example, an expert specialized at renewable energy management is assigned to evaluate the "technical maturity degree" or "social acceptability degree" of several candidate projects according to the established evaluation rule. He should select a corresponding language evaluation value from a linguistic term set to represent his preference on each alternative. However, due to the novelty of new energy technologies, according to the available information and his expertise in new energy management, he cannot choose only one linguistic evaluation value from the established linguistic terms set to represent his judgment. He hesitates among several options. In these similar situations, it is more reasonable to formulate a new decision-making rule or develop a tool that allows decision makers to express their preferences or judgments in a set of several objects with corresponding degrees of hesitation.

Hesitant fuzzy set is a useful tool firstly introduced by Torra [25], which is used for decision makers to provide their preferences on evaluating alternatives in context of high hesitation. Since the proposal of the concept, it has attracted much attention of researchers in related fields [26-31].

In order to deal with the hesitation in linguistic evaluation decision-making context, Rodriguez et al. [32] proposed the hesitant fuzzy linguistic term set (HFLTS) which can enable the decision makers to express their preference with several linguistic terms considering their hesitation, which is closer to the logic of human thinking. Since the proposal of the powerful HFLTS, lots of attention have been paid to it and some achievements have been obtained, such as group decisionmaking with comparative linguistic expression based on HFLTS [33], TOPSIS for HFLTS [34], comparison operators for HFLTS [35], hesitant linguistic information aggregation operators [36], distance and similarity measures for HFLTS [37], fuzzy envelope for hesitant fuzzy linguistic term set [38], hesitant fuzzy linguistic VIKOR [39], information entropy for HTLTS [40], hesitant fuzzy linguistic cross-entropy measures [41], hesitant fuzzy linguistic Maclaurin symmetric mean operators [42], interval-valued dual hesitant fuzzy uncertain linguistic aggregation operators [43], and hesitant fuzzy linguistic MACBETH method [44]. A survey of decisionmaking theory and methodologies of hesitant fuzzy linguistic term set has been also done [45]. From the literature reviews, we can see that more and more useful and novel comparison and aggregation operators based on hesitant fuzzy linguistic term set have been proposed. And new MCDM methods integrating classical MCDM methods with HFLTS to deal with hesitant fuzzy linguistic decision-making problems in different situations have been also developed. And their applications in hesitant fuzzy situation have also been extended.
Recently, several representative MCDM methods in hesitant linguistic context based on distance measure have been proposed. They are, respectively, hesitant fuzzy linguistic ordered weighted distance operators for group decisionmaking [46], hesitant fuzzy linguistic multigranularity decision-making model based on distance measures [47], cosine distance and similarity measures for HFLTSs [48], hesitant intuitionistic fuzzy linguistic distance measures [49], pairwise comparison and distance measure of hesitant fuzzy linguistic term sets [50], and the decision-making method based on the Hausdorff distance of hesitant fuzzy linguistic numbers [51], which quickly became a hot paper of high value.

However, to our knowledge, until now, very little work has been done about the MCDM problem in hesitant linguistic context considering the existence of interaction among criteria [52]. But in some decision-making process, the interaction among criteria is inevitable because it is costly or of great complexity to build a criteria set of which criteria are independent of each other in some situations [53-58]. So it is necessary to study the hesitant fuzzy linguistic MCDM with interactive criteria and develop a MCDM framework taking into consideration the interaction among criteria.

Because of the nature of HFLTS, an evaluation containing several fuzzy elements, the traditional method handling the interaction among criteria for MCDM in hesitant linguistic context from the perspective of information aggregation is not a good way to operate. Until now, few aggregation operators have been proposed directly operating on HFLTS. Chen and Hong [59] proposed a method by aggregating the fuzzy sets in each hesitant fuzzy linguistic term set into a fuzzy set and performed the a-cut operations to these aggregated fuzzy sets, which, to a certain extent, may not fully reflect the preference of decision makers. It is difficult to aggregate the interactive information by the existing conventional fusion techniques.

Multicriteria distance measure is a common decisionmaking approach and has been successfully used in MCDM to rank the alternatives by comparing the distances of the alternatives to the reference solution, such as the popular TOPSIS and VIKOR. Due to the valuable fuzzy distance measures for HFLTS, a novel way modeling the interaction among criteria of hesitant linguistic MCDM from the perspective of distance measure for collections of fuzzy-valued sets is more reasonable and necessary.

So, in this paper, motivated by the ordered weight distance (OWD) measure for sets emphasizing the ordered position importance of individual distance [60-62], induced ordered weighted averaging distance (IOWAD) [63, 64], intuitionistic fuzzy ordered weighted distance (IFOWD) operator [65], the Choquet integral [66], and discrete Choquet integral aggregating interacting criteria [67], several discrete Choquet integral distance measures modeling the interacting criteria from the perspective of distance measure are defined for collections of HFLTSs. A novel method using the fuzzy distance measure for two fuzzy-valued sets for hesitant fuzzy linguistic MCDM with interactive criteria is proposed. In this paper, always keep in mind that the preference of experts and 
interaction among criteria are, respectively, conducted by the HFLTS and the discrete Choquet integral distance measures.

The reminder of the paper is organized as follows: several preliminaries are provided in Section 2. Discrete Choquet integral distance measures modeling the interacting criteria from the perspective of distance measure are defined for collections of HFLTSs, respectively, in Section 3. In Section 4 , a method by using the fuzzy distance measure for two fuzzy-valued sets for hesitant fuzzy linguistic MCDM with interactive criteria is proposed. An illustrative example applied to renewable energy projects evaluation is given, and comparison analysis is also conducted in Section 5 (Table 4). Finally, a conclusion is drawn in Section 6.

\section{Preliminaries}

In this section, several basic concepts and related operational laws are briefly described, such as the basic concepts, aggregation operators, basic distance, and similarity measures for hesitant fuzzy set and hesitant fuzzy linguistic terms set. In addition, the ordered weighted distance measure is also given in this section.

2.1. Hesitate Fuzzy Set. Hesitant fuzzy sets (HFSs) were first introduced by Torra [25], which use several possible values between 0 and 1 to represent the membership degree of an element to a set. It is a powerful tool for decision makers to provide their preferences on objects with high degree of hesitation.

Definition 1 (see [25]). A hesitant fuzzy set on a fixed set $X$ is in terms of a function that when applied to $X$ a subset of $[0,1]$ returns, which can be represented as the following formation:

$$
E=\left\{\left\langle x, h_{E}(x)\right\rangle \mid x \in X\right\},
$$

where $h_{E}(x)$ is a set of values in $[0,1]$, denoting the possible membership degrees of the element $x \in X$ to the set $E$. For convenience, $h_{E}(x)$ is called a hesitant fuzzy element (HFE).

Definition 2 (see [26]). Suppose $h_{j}(j=1,2, \ldots, n)$ is a collection of HFEs, which constitute a hesitant fuzzy set. A generalized hesitant fuzzy weighted averaging (GHFWA) operator is a mapping GHFWA: $H^{n} \rightarrow H$ such that

$$
\begin{gathered}
\operatorname{GHFWA}_{\lambda}\left(h_{1}, h_{2}, \ldots, h_{n}\right)=\left(\bigoplus_{j=1}^{n}\left(w_{j} h_{j}{ }^{\lambda}\right)\right)^{1 / \lambda} \\
=\bigcup_{\gamma_{1} \in h_{1}, \gamma_{2} \in h_{2}, \ldots, \gamma_{n} \in h_{n}}\left\{\left(1-\prod_{j=1}^{n}\left(1-\gamma_{j}^{\lambda}\right)^{w_{j}}\right)^{1 / \lambda}\right\},
\end{gathered}
$$

where $W=\left(w_{1}, w_{2}, \ldots, w_{n}\right)$ is the associated weight vector of $h_{j}(j=1,2, \ldots, n), \sum_{j=1}^{n} w_{j}=1$. If $\lambda=1$ specially, the GHFWA operator reduces to the hesitant fuzzy weighted averaging operator.

2.2. Hesitate Fuzzy Linguistic Terms Set. The hesitant fuzzy linguistic terms set was proposed by Rodriguez et al. [32], and some operators including distance measures on HFLTS have been studied. Liu and Rodríguez [38] proposed a fuzzy envelope to carry out the computation process with HFLTS. In [68], the distance of two HFLTSs directly based on the hesitant fuzzy element index was defined.

Definition 3 (see [32]). Let $S=\left\{s_{0}, \ldots, s_{g}\right\}$ be a linguistic term set. A HFLTS, denoted by $H_{S}$, is an ordered finite subset of the consecutive linguistic terms of $S$.

Definition 4. Suppose that $H_{1}=\bigcup_{s_{\delta_{l}^{1}} \in H_{1}}\left\{s_{\delta_{l}^{1}} \mid l=1, \ldots, \# H_{1}\right\}$ and $H_{2}=\bigcup_{s_{\delta_{l}^{2}} \in H_{2}}\left\{s_{\delta_{l}^{2}} \mid l=1, \ldots, \# H_{2}\right\}$ are two HFLTSs on $X=\left\{x_{1}, x_{2}, \ldots, x_{n}\right\}$ defined on linguistic term set $S$ and $\# H_{1}$ and $\# H_{2}$ are the numbers of HFLTSs $H_{1}$ and $H_{2}$, respectively. Let $L=\max \left\{\# H_{1}, \# H_{2}\right\}$. If $\# H_{1} \neq \# H_{2}$, the shorter one should be extended to have the same number of linguistic terms as the other one by adding number of $\left|\# H_{1}-\# H_{2}\right|$ the lowest (resp., the greatest) term in the shorter one, if the decision maker in certain situation is pessimistic (resp., optimistic), which depends on the decision maker's risk preference, and the decision-making situations. Then the Hamming distance measure for two HFLTSs is defined as follows:

$$
d_{\mathrm{hd}}\left(H_{1}, H_{2}\right)=\frac{1}{L} \sum_{l=1}^{L} \frac{\left|\delta_{l}^{1}-\delta_{l}^{2}\right|}{g+1} \text {. }
$$

Definition 5. Fuzzy envelope of a hesitant fuzzy linguistic term set, denoted as env $\left(H_{S}\right)$, is a linguistic interval obtained by the upper boundary and low boundary of the HFLTS, which is defined as follows:

$$
\operatorname{env}\left(H_{S}\right)=\left[H_{S^{-}}, H_{S^{+}}\right] \text {, }
$$

where $H_{S^{+}}=\max \left(s_{j}\right), H_{S^{-}}=\min \left(s_{j}\right), s_{j} \in H_{S}, j=1,2$, ..., $\# H_{S}$.

2.3. The Ordered Weighted Distance Measure. The Hamming OWAD $[69,70]$ is an extension of the normalized weighted Hamming distance containing more information for distance measure of two sets. It can be seen as the combination of normal Hamming distance and the OWA operator. By using this distance measure, the importance of ordered position of the individual distances is considered, which means the larger (or smaller) individual deviations are assigned with higher (or lower) weights representing their influence degree on the global distance measure.

Definition 6. Let $A=\left\{a_{1}, a_{2}, \ldots, a_{n}\right\}$ and $B=\left\{b_{1}, b_{2}, \ldots, b_{n}\right\}$ be two evaluations sets. The Hamming OWAD of dimension $n$ is a mapping OWAD: $R^{n} \times R^{n} \rightarrow R$, with its associated weight vector $W=\left(w_{1}, w_{2}, \ldots, w_{n}\right), w_{i} \geq 0, \sum_{j=1}^{n} w_{j}=1$, $j=1,2, \ldots, n$; the OWAD measure is defined as follows:

$\operatorname{OWAD}(A, B)$

$=\operatorname{OWAD}\left(\left\langle a_{1}, b_{1}\right\rangle,\left\langle a_{2}, b_{2}\right\rangle, \ldots,\left\langle a_{n}, b_{n}\right\rangle\right)$

$=\sum_{j=1}^{n} w_{j} d_{j}$, 
where $d_{j}$ represents the $j$ th largest of the individual distance $\left|a_{j}-b_{j}\right|$.

The OWAD operator is commutative, monotonic, bounded, and idempotent, and it provides a parameterized family of distance measures ranging from the minimum to the maximum individual distance.

\section{2-Tuple Discrete Choquet Integral Distance Measures for Collections of HFLTSs}

Distance measure can be applied widely to various fields, such as medical diagnosis, pattern and image recognition, approximate reasoning, cluster analysis, recommend systems, and decision-making. Lots of work about distance measure has been done on fuzzy sets and intuitionistic fuzzy sets, and a variety of distance measures for hesitant fuzzy sets have been also developed. Recently, hesitant fuzzy linguistic ordered weighted distance operators for group decision-making [46], and the decision-making methods based on the Hausdorff distance of hesitant fuzzy linguistic number [51] have been proposed. Because of the flexibility and special features of HFLTS in certain situations, it is necessary to develop the distance measures for collections of HFLTSs for MCDM. In this section, we propose several distance measures for sets of interactive elements, mainly for the collections of HFLTSs with interactive elements based on the 2-tuple linguistic representation approach, fuzzy measure, and the discrete Choquet integral.

\subsection{Fuzzy Measure and Discrete Choquet Integral}

Definition 7 (see [71]). A fuzzy measure on a measure space set $C$ is a set function $\mu: \mathscr{P}(C) \rightarrow[0,1]$, which satisfy the following axioms:

(i) $\mu(\phi)=0, \mu(C)=1$;

(ii) $B \subseteq Q \subseteq C$ implies $\mu(B) \leq \mu(Q)$.

For all disjoint subsets $B \subseteq Q \subseteq C$,

(i) if $\mu(B \cup \mathrm{Q}) \leq \mu(B)+\mu(\mathrm{Q})$, the fuzzy measure is said to be subadditive, which means there is a negative interaction between $B$ and $Q$ (or we say they are redundant or substitutive);

(ii) if $\mu(B \cup Q) \geq \mu(B)+\mu(Q)$, the fuzzy measure is said to be superadditive, which means there is a positive synergetic interaction between $B$ and $Q$ (or we say they are complementary);

(iii) Particularly, if, for all $B \subseteq Q \subseteq C, \mu(B \cup Q)=$ $\mu(B)+\mu(Q)$, we say the fuzzy measure is additive, which means there is no interaction between $B$ and $Q$ and all the elements in $C$ are independent, we have

$$
\mu(B)=\sum_{c_{i} \in B} \mu\left(c_{i}\right), \quad \forall B \subseteq C .
$$

For a MCDM framework with fuzzy measure $\mu(B)$, the component $\mu(B)$ can be interpreted as the importance of subset $B \subseteq C$. A fuzzy measure for subsets of $C$ is monotonous, which means that when new criteria are added to a subset of $C$, the importance of the expanded subset does not decrease. And due to the main feature of a fuzzy measure, nonadditive, it is able to be used to represent various kinds of interactions among the elements of a set (the decision criteria); the interactions may range from redundancy (negative interactions) to synergy (positive interaction).

In actual practice, fuzzy measure plays a role similar to the one of weights in the weighted mean operators. They are used to represent the importance or relevance of a set. Thus with the separate weights of criteria, weights of any combination of criteria can also be defined. And the ability of the Choquet integral to deal with interaction among criteria is due to the fact that a weight of importance is attributed to every subset of criteria.

When a fuzzy measure is employed to represent the importance degree of the subsets of criteria set, a suitable aggregation function is called the Choquet integral.

Definition 8 (see $[72,73]$ ). Let $\mu$ be a fuzzy measure on $C$ and $f$ be a positive real-valued function on $C$, the discrete Choquet integral on $f$ with respective to $\mu$ is defined as follows:

$$
C_{\mu}(f)=\sum_{i=1}^{n} f\left(c_{\sigma(i)}\right)\left[\mu\left(C_{\sigma(i)}\right)-\mu\left(C_{\sigma(i+1)}\right)\right],
$$

where $(\sigma(1), \sigma(2), \ldots, \sigma(n))$ is a permutation of $(1,2, \ldots, n)$, so that $0 \leq f_{\sigma(1)} \leq f_{\sigma(2)} \leq \cdots \leq f_{\sigma(n)}, C_{\sigma(i)}=\left\{c_{\sigma(i)}\right.$, $\left.c_{\sigma(i+1)}, \ldots, c_{\sigma(n)}\right\}, C_{\sigma(n+1)}=\phi$.

\subsection{Definition of Generalized Discrete Choquet Integral \\ Distance Measure and Normalized Discrete Choquet Integral Hamming Distance}

\section{(1) The Generalized Definition of Discrete Choquet Integral Distance Measure for MCDM}

Definition 9. For two evaluation values sets $A=\left\{a_{1}\right.$, $\left.a_{2}, \ldots, a_{n}\right\}$ and $B=\left\{b_{1}, b_{2}, \ldots, b_{n}\right\}$ with respect to criteria set $C$ of $n$ elements, let $\mu$ be a fuzzy measure on $C$ and let $d\left(a_{i}, b_{i}\right)(i=1,2, \ldots, n)$ be normalized positive realvalued individual distance measure functions with respect to the type of the values; a Choquet integral distance measure $\mathrm{CHD}_{\mu}(A, B)=\bigoplus_{i=1}^{n} d_{\sigma(i)}\left(a_{i}, b_{i}\right)\left[\mu\left(C_{\sigma(i)}\right)-\mu\left(C_{\sigma(i+1)}\right)\right]$ is a definition which satisfy the following axioms:

(i) $0 \leq \operatorname{CHD}_{\mu}(A, B) \leq 1$;

(ii) $\operatorname{CHD}_{\mu}(A, B)=0$, if $A=B$;

(iii) $\operatorname{CHD}_{\mu}(A, B)=\operatorname{CHD}_{\mu}(B, A)$.

\section{(2) A Normalized Discrete Choquet Integral Hamming Distance (CHD)}

Definition 10. For two evaluation values sets $A=$ $\left\{a_{1}, a_{2}, \ldots, a_{n}\right\}$ and $B=\left\{b_{1}, b_{2}, \ldots, b_{n}\right\}$ with respect to criteria set $C$ of $n$ elements, let $\mu$ be a fuzzy measure on $C$; a 
normalized discrete Choquet integral Hamming distance $(\mathrm{CHD})$ of dimension $n$ is a mapping $[0,1]^{n} \times[0,1]^{n} \rightarrow[0,1]$, which is defined as follows:

$$
\begin{aligned}
& \mathrm{CHD}_{\mu}(A, B) \\
& \quad=\frac{1}{n} \sum_{i=1}^{n}\left(\left|a_{\sigma(i)}-b_{\sigma(i)}\right| \cdot\left[\mu\left(C_{\sigma(i)}\right)-\mu\left(C_{\sigma(i+1)}\right)\right]\right),
\end{aligned}
$$

where $(\sigma(1), \sigma(2), \ldots, \sigma(n))$ is a permutation of $(1,2, \ldots, n)$, so that $\left|a_{\sigma(1)}-b_{\sigma(1)}\right| \leq\left|a_{\sigma(2)}-b_{\sigma(2)}\right| \leq \cdots \leq\left|a_{\sigma(n)}-b_{\sigma(n)}\right|$, $C_{\sigma(i)}=\left\{c_{\sigma(i)}, c_{\sigma(i+1)}, \ldots, c_{\sigma(n)}\right\}, C_{\sigma(n+1)}=\phi$.

The definition satisfies the properties (i), (ii), and (iii) of the discrete Choquet integral distance measure.

Proof. (i) Because $\mu\left(C_{\sigma(i)}\right)$ and $\mu\left(C_{\sigma(i+1)}\right)$ are two fuzzy measures whose values are in the interval $[0,1]$, for $\mu\left(C_{\sigma(i)}\right) \supseteq$ $\mu\left(C_{\sigma(i+1)}\right)$, because $\mu\left(C_{\sigma(i)}\right) \geq \mu\left(C_{\sigma(i+1)}\right)$, so $0 \leq \mu\left(C_{\sigma(i)}\right)-$ $\mu\left(C_{\sigma(i+1)}\right) \leq 1 ;\left|a_{\sigma(i)}-b_{\sigma(i)}\right|,(i=1,2, \ldots, n)$ are individual Hamming distance measures, $0 \leq\left|a_{\sigma(i)}-b_{\sigma(i)}\right| \leq 1$; particularly, when $i=n, \mu\left(C_{\sigma(i)}\right)-\mu\left(C_{\sigma(i+1)}\right)=1$, if $\mid a_{\sigma(n)}-$ $b_{\sigma(n)} \mid=1$, then $\operatorname{CHD}_{\mu}(A, B)=1$, so we can get that $0 \leq$ $(1 / n) \sum_{i=1}^{n}\left(\left|a_{\sigma(i)}-b_{\sigma(i)}\right| \cdot\left[\mu\left(C_{\sigma(i)}\right)-\mu\left(C_{\sigma(i+1)}\right)\right]\right) \leq 1$.

(ii) If $A=B, a_{i}=b_{i}(i=1,2, \ldots, n)$, then $\mid a_{\sigma(i)}-$ $b_{\sigma(i)} \mid=0(i=1,2, \ldots, n),(1 / n) \sum_{i=1}^{n}\left(\left|a_{\sigma(i)}-b_{\sigma(i)}\right| \cdot\left[\mu\left(C_{\sigma(i)}\right)-\right.\right.$ $\left.\left.\mu\left(C_{\sigma(i+1)}\right)\right]\right)=0$.

(iii) For $\left|a_{\sigma(i)}-b_{\sigma(i)}\right|=\left|b_{\sigma(i)}-a_{\sigma(i)}\right|(i=1,2, \ldots, n)$, then

$$
\begin{aligned}
& \frac{1}{n} \sum_{i=1}^{n}\left(\left|a_{\sigma(i)}-b_{\sigma(i)}\right| \cdot\left[\mu\left(C_{\sigma(i)}\right)-\mu\left(C_{\sigma(i+1)}\right)\right]\right) \\
& \quad=\frac{1}{n} \sum_{i=1}^{n}\left(\left|b_{\sigma(i)}-a_{\sigma(i)}\right| \cdot\left[\mu\left(C_{\sigma(i)}\right)-\mu\left(C_{\sigma(i+1)}\right)\right]\right), \\
& \mathrm{CHD}_{\mu}(A, B)=\mathrm{CHD}_{\mu}(B, A) .
\end{aligned}
$$

3.3. 2-Tuple Discrete Choquet Integral Distance Measure for Collections of HFLTSs. The 2-tuple linguistic information is the evaluation result expressed in 2-tuple $\left(s_{k}, \alpha_{k}\right)$, where $s_{k}$ is the $k$ th element in the predefined language evaluation set $S$; it means the closest language phrase in the linguistic assessment information given or got to original language evaluation set; $\alpha_{k}$ is called symbolic transfer value, which represents the deviation between $s_{k}$ and the evaluation result and satisfies $\alpha_{k} \in(-0.5,0.5]$.

Definition 11 (see [74]). Suppose that a real number $\beta \epsilon$ $[0, Z]$, where $Z$ is the number of elements in set $S ; \beta$ is represented as 2-tuple information by the following function $\Delta:$

$$
\begin{aligned}
& \Delta:[0, Z] \longrightarrow S \times[-0.5,0.5), \\
& \Delta(\beta)= \begin{cases}s_{k}, & k=\operatorname{round}(\beta) \\
\alpha_{k}=\beta-k, & \alpha_{k} \in[-0.5,0.5),\end{cases}
\end{aligned}
$$

Given a 2-tuple linguistic value $\left(s_{k}, \alpha_{k}\right)$, there is an inverse function $\Delta^{-1}$, which can convert $\left(s_{k}, \alpha_{k}\right)$ into a numerical value $\beta \in[0, Z]$ :

$$
\begin{aligned}
\Delta^{-1}: S \times[-0.5,0.5) & \longrightarrow[0, Z], \\
\Delta^{-1}\left(s_{k}, \alpha_{k}\right) & =k+\alpha_{k}=\beta .
\end{aligned}
$$

Definition 12 (see [75]). Let $s_{m}, s_{n} \in S$ be two linguistic terms defined on linguistic terms set $S=\left\{s_{0}, \ldots, s_{g}\right\}$; then the distance between two linguistic terms $d\left(s_{m}, s_{n}\right)$ can be defined as follows:

$$
d\left(s_{m}, s_{n}\right)=\frac{|m-n|}{g+1} .
$$

Definition 13. Let $\left(s_{m}, \alpha_{m}\right),\left(s_{n}, \alpha_{n}\right)$ be two 2-tuple linguistic representations defined on linguistic terms set $S=$ $\left\{s_{0}, \ldots, s_{g}\right\}$; then the distance between two 2-tuple linguistic representations $d\left(\left(s_{m}, \alpha_{m}\right),\left(s_{n}, \alpha_{n}\right)\right)$ can be defined as follows:

$$
d\left(\left(s_{m}, \alpha_{m}\right),\left(s_{n}, \alpha_{n}\right)\right)=\frac{\left|\Delta^{-1}\left(s_{m}, \alpha_{m}\right)-\Delta^{-1}\left(s_{n}, \alpha_{n}\right)\right|}{g+1} .
$$

Definition 14. For two fuzzy-valued sets $\widetilde{A}=\left(\widetilde{a}_{1}, \widetilde{a}_{2}, \ldots, \widetilde{a}_{n}\right)$ and $\widetilde{B}=\left(\widetilde{b}_{1}, \widetilde{b}_{2}, \ldots, \widetilde{b}_{n}\right)$ on criteria set $C, \widetilde{a}_{i}$ and $\widetilde{b}_{i}$ are 2 tuple hesitant fuzzy linguistic terms sets defined on linguistic terms set $S=\left\{s_{0}, \ldots, s_{g}\right\}$, which are represented as $\widetilde{a}_{i}=\bigcup_{\left(s_{\delta_{l}} \tilde{a}_{i}, \alpha_{\delta_{l}} \widetilde{a}_{i}\right) \in \widetilde{a}_{i}}\left\{\left(s_{\delta_{l} \widetilde{a}_{i}}, \alpha_{\delta_{l}{\widetilde{a_{i}}}_{i}} \mid l=1, \ldots, \# \widetilde{a}_{i}\right\}\right.$ and $\widetilde{b}_{i}=$ $\left.\bigcup_{\left(s_{\delta_{l}}, \alpha \tilde{\delta}_{l}\right.}\right) \in \widetilde{b}_{i}\left\{\left(s_{\delta_{l} \tilde{b}_{i}}, \alpha_{\delta_{l}^{\tilde{b}_{i}}}\right) \mid l=1, \ldots, \# \widetilde{b}_{i}\right\} ; \# \widetilde{a}_{i}$ and $\widetilde{b}_{i}$ are the numbers of HFLTSs $\tilde{a}_{i}$ and $\tilde{b}_{i}$, respectively. When all the 2tuple linguistic transfer values $\alpha_{i}$ in a 2-tuple HFLTS are assigned a value of zero, the 2-tuple HFLTS become a common HFLTS. Let $L=\max \left\{\# \widetilde{a}_{i}, \# \widetilde{b}_{i}\right\}$. If $\# \widetilde{a}_{i} \neq \# \widetilde{b}_{i}$, the shorter one would be extended to have the same number of linguistic terms as the other one by adding number of $\left|\# \widetilde{a}_{i}-\# \widetilde{b}_{i}\right|$ the lowest (resp., greatest) term in the shorter one, if the decision maker in certain decision-making situation is pessimistic (resp., optimistic), which depends on the decision maker's risk preference, and the decision-making situations. Let $\mu$ be a fuzzy measure on $C$; then the discrete Choquet integral distance measure for collections of HFLTSs (CDHLS) based on 2-tuple representation and discrete Choquet integral is a mapping $[0,1]^{n} \times[0,1]^{n} \rightarrow[0,1]$, which is defined as follows:

$$
\begin{aligned}
& \operatorname{CDHLS}_{\mu}(\widetilde{A}, \widetilde{B})=\sum_{i=1}^{n}\left(\left(\frac{1}{L}\right.\right. \\
& \left.\cdot \sum_{l=1}^{L}\left|\frac{\Delta^{-1}\left(s_{\delta_{l}^{\tilde{a}_{\sigma(i)}},}, \alpha_{\delta_{l}^{\tilde{\sigma}_{\sigma(i)}}}\right)-\Delta^{-1}\left(s_{\delta_{l}^{\tilde{b}_{\sigma(i)}}}, \alpha_{\delta_{l}^{\tilde{b}_{\sigma(i)}}}\right)}{g+1}\right|\right) \\
& \left.\cdot\left[\mu\left(C_{\sigma(i)}\right)-\mu\left(C_{\sigma(i+1)}\right)\right]\right),
\end{aligned}
$$

where round $(\cdot)$ is a rounding function. 
where $(\sigma(1), \sigma(2), \ldots, \sigma(n))$ is a permutation of $(1,2, \ldots, n)$, so that

$$
\begin{aligned}
& d\left(\widetilde{a}_{\sigma(1)}, \widetilde{b}_{\sigma(1)}\right) \leq d\left(\tilde{a}_{\sigma(2)}, \widetilde{b}_{\sigma(2)}\right) \leq \cdots \\
& \quad \leq d\left(\widetilde{a}_{\sigma(n)}, \widetilde{b}_{\sigma(n)}\right), \\
& d\left(\widetilde{a}_{\sigma(i)}, \widetilde{b}_{\sigma(i)}\right) \\
& \quad=\frac{1}{L} \sum_{l=1}^{L}\left|\frac{\Delta^{-1}\left(s_{\delta_{l}^{a_{\sigma(i)}}}, \alpha_{\delta_{l}^{\tilde{a}_{\sigma(i)}}}\right)-\Delta^{-1}\left(s_{\delta_{l}^{\tilde{b}_{\sigma(i)}}}, \alpha_{\delta_{l}^{\tilde{b}_{\sigma(i)}}}\right)}{g+1}\right| \\
& C_{\sigma(i)}=\left\{c_{\sigma(i)}, c_{\sigma(i+1)}, \ldots, c_{\sigma(n)}\right\}, \\
& C_{\sigma(n+1)}=\phi .
\end{aligned}
$$

The definition of 2-tuple discrete Choquet integral distance measure for collections of HFLTSs above satisfies the following axioms:

(i) $0 \leq \operatorname{CDHLS}_{\mu}(\widetilde{A}, \widetilde{B}) \leq 1$;

(ii) $\operatorname{CDHLS}_{\mu}(\widetilde{A}, \widetilde{B})=0$, if $\widetilde{A}=\widetilde{B}$;

(iii) $\operatorname{CDHLS}_{\mu}(\widetilde{A}, \widetilde{B})=\operatorname{CDHLS}_{\mu}(\widetilde{B}, \widetilde{A})$.

Proof. (i) Because $\mu\left(C_{\sigma(i)}\right)$ and $\mu\left(C_{\sigma(i+1)}\right)$ are two fuzzy measures whose values are in the interval $[0,1]$, for
$\mu\left(C_{\sigma(i)}\right) \supseteq \mu\left(C_{\sigma(i+1)}\right)$, because $\mu\left(C_{\sigma(i)}\right) \geq \mu\left(C_{\sigma(i+1)}\right)$, so $0 \leq \mu\left(C_{\sigma(i)}\right)-\mu\left(C_{\sigma(i+1)}\right) \leq 1$. Besides, for $-0.5 \leq$ $\Delta^{-1}\left(s_{\delta_{l}^{\tilde{i}_{i}}}, \alpha_{\delta_{l}^{\tilde{i}_{i}}}\right), \Delta^{-1}\left(s_{\delta_{l}^{\tilde{b}_{i}}}, \alpha_{\delta_{l}^{\tilde{b}_{i}}}\right) \leq g+0.5$, then $0 \leq \mid\left(\Delta^{-1}\left(s_{\delta_{l}^{\tilde{a}_{i}}}\right.\right.$, $\left.\left.\alpha_{\delta_{l}^{\tilde{a}_{i}}}\right)-\Delta^{-1}\left(s_{\delta_{l}^{\tilde{b}_{i}}}, \alpha_{\delta_{l}^{\tilde{b}_{i}}}\right)\right) /(g+1) \mid \leq 1$; then we get $0 \leq(1 /$ L) $\sum_{l=1}^{L}\left|\left(\Delta^{-1}\left(s_{\delta_{l}^{\tilde{z}_{i}}}, \alpha_{\delta_{l}^{\tilde{a}_{i}}}\right)-\Delta^{-1}\left(s_{\delta_{l}^{\tilde{b}_{i}}}, \alpha_{\delta_{i}^{\tilde{b}_{i}}}\right)\right) /(g+1)\right| \leq 1,(i=1,2$, $\ldots, n)$; particularly, suppose all the individual distances have the max distances, which are that $(1 / L) \sum_{l=1}^{L} \mid\left(\Delta^{-1}\left(s_{\delta_{l}^{\tilde{i}_{i}}}, \alpha_{\delta_{l}^{\tilde{q}_{i}}}\right)-\right.$ $\left.\Delta^{-1}\left(s_{\delta_{l}^{\tilde{b}_{i}}}, \alpha_{\delta_{l}^{\tilde{b}_{i}}}\right)\right) /(g+1) \mid=1$; then the distance of the collections is as follows: $\operatorname{CDHLS}_{\mu}(\widetilde{A}, \widetilde{B})=1 \cdot\left(\mu\left(C_{\sigma(1)}\right)-\right.$ $\left.\mu\left(C_{\sigma(2)}\right)+\mu\left(C_{\sigma(2)}\right)-\mu\left(C_{\sigma(3)}\right)+\mu\left(C_{\sigma(n)}\right)-\mu\left(C_{\sigma(n+1)}\right)\right)=$ $\mu\left(C_{\sigma(1)}\right)-\mu\left(C_{\sigma(n+1)}\right)=1$, so we can get that $0 \leq$ $\mathrm{CDHLS}_{\mu}(\widetilde{A}, \widetilde{B}) \leq 1$.

(ii) If $\widetilde{A}=\widetilde{B}$, which is that all $\widetilde{a}_{i}=\widetilde{b}_{i}(i=1,2, \ldots, n)$, then $\operatorname{CDHLS}_{\mu}(\widetilde{A}, \widetilde{B})=(1 / n) \sum_{i=1}^{n}\left(0 \cdot\left[\mu\left(C_{\sigma(i)}\right)-\mu\left(C_{\sigma(i+1)}\right)\right]\right)=0$.

(iii) For $\left|\Delta^{-1}\left(s_{\delta_{l}^{\tilde{a}_{i}},}, \alpha_{\delta_{l}^{\tilde{a}_{i}}}\right)-\Delta^{-1}\left(s_{\delta_{l}^{\bar{b}_{i}}}, \alpha_{\delta_{l}^{\bar{b}_{i}}}\right)\right|=\mid \Delta^{-1}\left(s_{\delta_{l}^{\tilde{b}_{i}}}, \alpha_{\delta_{l}^{\tilde{b}_{i}}}\right)-$ $\Delta^{-1}\left(s_{\delta_{l}^{\bar{i}_{i}}}, \alpha_{\left.\delta_{l}^{\bar{i}_{i}}\right)}\right)(i=1,2, \ldots, n)$, then, $\operatorname{CDHLS}_{\mu}(\widetilde{A}, \widetilde{B})=$ $\operatorname{CDHLS}_{\mu}(\widetilde{B}, \widetilde{A})$.

Definition 15. For the 2-tuple hesitant linguistic fuzzy-valued sets $\widetilde{A}=\left(\widetilde{a}_{1}, \widetilde{a}_{2}, \ldots, \widetilde{a}_{n}\right)$ and $\widetilde{B}=\left(\widetilde{b}_{1}, \widetilde{b}_{2}, \ldots, \widetilde{b}_{n}\right)$ defined above, a generalized Choquet integral distance measure for collections of HFLTSs (GCDHLS) is defined as follows:

$$
\operatorname{GCDHLS}_{\mu}(\widetilde{A}, \widetilde{B})=\left(\sum_{i=1}^{n}\left(\left(\frac{1}{L} \sum_{l=1}^{L}\left|\frac{\Delta^{-1}\left(s_{\delta_{l}^{\tilde{\sigma}_{(i)}}}, \alpha_{\delta_{l}^{\tilde{\sigma}_{\sigma(i)}}}\right)-\Delta^{-1}\left(s_{\delta_{l}^{\tilde{\sigma}_{(i)}}}, \alpha_{\delta_{l}^{\tilde{\sigma}_{(i)}}}\right)}{g+1}\right|^{\lambda}\right) \cdot\left[\mu\left(C_{\sigma(i)}\right)-\mu\left(C_{\sigma(i+1)}\right)\right]\right)\right)^{1 / \lambda} .
$$

Definition 16. For the 2-tuple hesitant linguistic fuzzy-valued sets $\widetilde{A}=\left(\widetilde{a}_{1}, \widetilde{a}_{2}, \ldots, \widetilde{a}_{n}\right)$ and $\widetilde{B}=\left(\widetilde{b}_{1}, \widetilde{b}_{2}, \ldots, \widetilde{b}_{n}\right)$ defined above, a Choquet integral Hausdorff distance measure for collections of HFLTSs (CHDHLS) is defined as follows:

$$
\begin{aligned}
& \operatorname{CHDHLS}_{\mu}(\widetilde{A}, \widetilde{B})=\max _{i=1}^{n}\left(\frac{1}{L}\right. \\
& \left.\cdot \sum_{l=1}^{L}\left|\frac{\Delta^{-1}\left(s_{\delta_{l}^{\tilde{\sigma}_{(i)}}}, \alpha_{\delta_{l}^{\bar{\sigma}_{\sigma(i)}}}\right)-\Delta^{-1}\left(s_{\delta_{l}^{\tilde{\sigma}_{\sigma(i)}}}, \alpha_{\delta_{l}^{\tilde{b}_{\sigma(i)}}}\right)}{g+1}\right|\right) \\
& \cdot\left[\mu\left(C_{\sigma(i)}\right)-\mu\left(C_{\sigma(i+1)}\right)\right] .
\end{aligned}
$$

Compared to the normal distance measures which suppose the elements in the sets are independent, the Choquet integral distance measures can take into consideration the interaction factor among the criteria, which can be used to deal with the nonadditive distance measure for sets.
Some special cases of Choquet integral distance measure for collections of HFLTSs (CDHLS) are discussed as follows.

(i) If the fuzzy measure $\mu$ is an additive fuzzy measure, then $\mu\left(C_{\sigma(i)}\right)-\mu\left(C_{\sigma(i+1)}\right)=\mu\left(c_{\sigma(i)}\right), i=1,2, \ldots, n$; in this case, the normalized Choquet integral distance measure for collections of HFLTSs (CDHLS) reduces to the normalized weighted Hamming distance for collections of HFLTSs:

$$
\begin{aligned}
& \operatorname{WDHLS}_{\mu}(\widetilde{A}, \widetilde{B})=\sum_{i=1}^{n}\left(\left(\frac{1}{L}\right.\right. \\
& \left.\cdot \sum_{l=1}^{L}\left|\frac{\Delta^{-1}\left(s \delta_{l}^{\tilde{a}_{\sigma(i)}}, \alpha_{\delta_{l}^{\tilde{\sigma}_{\sigma(i)}}}\right)-\Delta^{-1}\left(s \delta_{l}^{\tilde{\sigma}_{\sigma(i)}}, \alpha_{\tilde{\sigma}_{l}}\right)}{g+1}\right|\right) \\
& \left.\cdot \mu\left(c_{i}\right)\right) .
\end{aligned}
$$


(ii) If $\mu(Y)=\sum_{i=1}^{|\mathrm{Y}|} \omega_{i}$, for all $Y \subseteq C$, where $|Y|$ is the number of the elements in $Y$, then $w_{i}=\mu\left(C_{\sigma(i)}\right)-\mu\left(C_{\sigma(i+1)}\right)$, $i=1,2, \ldots, n$; here $W=\left(w_{1}, w_{2}, \ldots, w_{n}\right), w_{i} \geq 0, i=$ $1,2, \ldots, n, \sum_{i=1}^{n} w_{i}=1$; in this case, the normalized Choquet integral distance measure for collections of HFLTSs (CDHLS) reduces to the normalized ordered weighted distance for collections of HFLTSs (OWDHLS):

$$
\begin{aligned}
& \operatorname{OWDHLS}_{\mu}(\widetilde{A}, \widetilde{B})=\sum_{i=1}^{n}\left(\left(\frac{1}{L}\right.\right. \\
& \left.\cdot \sum_{l=1}^{L}\left|\frac{\Delta^{-1}\left(s_{\delta_{l}^{a_{\sigma(i)}}}, \alpha_{\delta_{l}^{\tilde{a}_{\sigma(i)}}}\right)-\Delta^{-1}\left(s_{\delta_{l}^{\tilde{\sigma}_{\sigma(i)}}}, \alpha_{\delta_{l}^{\tilde{\sigma}_{\sigma(i)}}}\right)}{g+1}\right|\right) \\
& \left.\cdot \omega_{i}\right),
\end{aligned}
$$

where $(\sigma(1), \sigma(2), \ldots, \sigma(n))$ is a permutation of $(1,2, \ldots, n)$, so that

$$
\begin{aligned}
& d\left(\widetilde{a}_{\sigma(1)}, \widetilde{b}_{\sigma(1)}\right) \leq d\left(\widetilde{a}_{\sigma(2)}, \widetilde{b}_{\sigma(2)}\right) \leq \cdots \\
& \leq d\left(\widetilde{a}_{\sigma(n)}, \widetilde{b}_{\sigma(n)}\right), \\
& d\left(\widetilde{a}_{\sigma(i)}, \widetilde{b}_{\sigma(i)}\right) \\
& =\frac{1}{L} \sum_{l=1}^{L}\left|\frac{\Delta^{-1}\left(s_{\delta_{l}^{\tilde{a}_{\sigma(i)}},}, \alpha_{\delta_{l}^{\tilde{a}_{\sigma(i)}}}\right)-\Delta^{-1}\left(s_{\delta_{l}^{\tilde{b}_{(i)}}}, \alpha_{\delta_{l}^{\tilde{b}_{\sigma(i)}}}\right)}{g+1}\right| .
\end{aligned}
$$

(iii) If $\mu(Y)=1$, for all $Y \subseteq C$, then

$$
\begin{aligned}
& \operatorname{CDHLS}_{\mu}(\widetilde{A}, \widetilde{B}) \\
& \quad=\max \left\{d\left(\widetilde{a}_{1}, \widetilde{b}_{1}\right), d\left(\widetilde{a}_{2}, \widetilde{b}_{2}\right), \ldots, d\left(\widetilde{a}_{n}, \widetilde{b}_{n}\right)\right\} \\
& \quad=d\left(\widetilde{a}_{\sigma(n)}, \widetilde{b}_{\sigma(n)}\right) .
\end{aligned}
$$

(iv) If $\mu(Y)=0$, for any $Y \subset C$, and $Y \neq C$, then

$$
\begin{aligned}
& \operatorname{CDHLS}_{\mu}(\widetilde{A}, \widetilde{B}) \\
& \quad=\min \left\{d\left(\widetilde{a}_{1}, \widetilde{b}_{1}\right), d\left(\widetilde{a}_{2}, \widetilde{b}_{2}\right), \ldots, d\left(\widetilde{a}_{n}, \widetilde{b}_{n}\right)\right\} \\
& \quad=d\left(\widetilde{a}_{\sigma(1)}, \widetilde{b}_{\sigma(1)}\right),
\end{aligned}
$$

where $(\sigma(1), \sigma(2), \ldots, \sigma(n))$ is a permutation of $(1,2, \ldots, n)$, so that

$$
\begin{aligned}
& d\left(\widetilde{a}_{\sigma(1)}, \widetilde{b}_{\sigma(1)}\right) \leq d\left(\widetilde{a}_{\sigma(2)}, \widetilde{b}_{\sigma(2)}\right) \leq \cdots \\
& \quad \leq d\left(\widetilde{a}_{\sigma(n)}, \widetilde{b}_{\sigma(n)}\right), \\
& d\left(\tilde{a}_{\sigma(i)}, \widetilde{b}_{\sigma(i)}\right) \\
& \quad=\frac{1}{L} \sum_{l=1}^{L}\left|\frac{\Delta^{-1}\left(s_{\delta_{l}^{\tilde{a}_{\sigma(i)}}}, \alpha_{\delta_{l}^{\tilde{a}_{\sigma(i)}}}\right)-\Delta^{-1}\left(s_{\delta_{l}^{\tilde{b}_{\sigma(i)}}}, \alpha_{\delta_{l}^{\tilde{b}_{\sigma(i)}}}\right)}{g+1}\right| .
\end{aligned}
$$

\section{Method for Hesitant Fuzzy Linguistic MCDM with Interactive Criteria}

The core idea of MCDM methods based on aggregation operator is that, firstly, we aggregate evaluation values on each criteria for each alternative by using a specific aggregation operator to get a collective value for each alternative; then, we rank the collective evaluations of each alternative based on some appropriate comparison rules.

As a comparison, the main idea or methodology of decision-making methods based on distance measure, such the TOPSIS or VIKOR, is that, firstly, we determine the reference values on each criterion, that is, determine the ideal or reference solution; then, we calculate the distances of each solution to the reference solution and rank alternatives based on the distances.

In this section, we propose a multicriteria decisionmaking framework of hesitant fuzzy linguistic sets with interactive criteria. The decision-making framework is built from the perspective of distance measure based on the 2-tuple linguistic representation approach and the discrete Choquet integral.

In some cases, the cost of establishing a set of criteria that are independent with each other is relatively high, or it is impossible to establish fully independent sets of decision criteria due to the highly complex decision scenarios. Consider a MCDM problem, of which the criteria may be interactive. The candidates set is denoted as $X=\left\{x_{1}, x_{2}, \ldots, x_{m}\right\}$, and the criteria set is denoted as $C=\left\{c_{1}, c_{2}, \ldots, c_{n}\right\}$; the evaluation value of the $i$ th alternative on the $j$ th criterion given by expert is denoted as $p_{i j}$. Then the decision-making matrix given by expert with interactive criteria is represented as follows:

$$
P=\left[\begin{array}{ccccc}
p_{1 j} & \cdots & p_{1 j} & \cdots & p_{1 n} \\
\vdots & & \vdots & & \vdots \\
p_{i 1} & \ddots & p_{i j} & \ddots & p_{i n} \\
\vdots & & \vdots & & \vdots \\
p_{m n} & \cdots & p_{m j} & \cdots & p_{m n}
\end{array}\right] .
$$

Due to the high complexity of the decision-making problem, the decision organizers intend to require the experts to use linguistic values to represent their evaluation values on 
each criteria for candidate alternatives, and they have built a basic linguistic terms set $S=\left\{s_{0}, \ldots, s_{g}\right\}$. However, the limited recognition of experts results in the experts not being able to choose only one linguistic term to represent their preference, and they hesitate among several linguistic terms of high hesitation.

Suppose the fuzzy measure on criteria set $C$ and the subsets of $C$ is $\mu: \mathscr{P}(C) \rightarrow[0,1]$.

The decision-making procedure for hesitant fuzzy linguistic MCDM with interactive criteria based on the 2-tuple linguistic representation approach and the discrete Choquet integral is as follows.

Step 1. Confirm the fuzzy measure on criteria set $C$ and the subsets of $C$, which is denoted as $\mu: \mathscr{P}(C) \rightarrow[0,1]$. Several methods for determining the fuzzy measure on one particular set have been proposed, such as the heuristic-based methods [76], the fuzzy identification method based on the semantics [77], genetic algorithms [78], and the novel $\lambda$-fuzzy measure method [79].

Step 2. Determine the reference solution. The most popular reference solutions used are the positive-ideal solution $\eta^{+}=\left(\eta_{1}^{+}, \eta_{2}^{+}, \ldots, \eta_{n}^{+}\right)$and the negative-ideal solution $\eta^{-}=$ $\left(\eta_{1}^{-}, \eta_{2}^{-}, \ldots, \eta_{n}^{-}\right), j=1,2, \ldots, n$. Let $C_{1}$ be a collection of benefit criteria and $C_{2}$ be a collection of cost criteria.

Inspired by the method comparing two hesitate fuzzy elements (HFEs) proposed by [26], for a HFLTS $h, s(h)=$ $(1 / l(h)) \sum_{\gamma \in h} \Delta^{-1}(\gamma)$ is the score function of $h$, where $l(h)$ is the number of elements in $h$ and $\Delta^{-1}(\cdot)$ is the 2-tuple transfer function. Here we introduce the envelope for HFLTS proposed by [32] as a comparison parameter denoted as $\operatorname{env}(h)$. In this paper, we combined $\operatorname{env}(h)$ and $s(h)$ to compare two HFLTSs $h_{1}$ and $h_{2}$.

(i) If $s\left(h_{1}\right)>s\left(h_{2}\right)$, then $h_{1}$ is superior to $h_{2}$, denoted by $h_{1}>h_{2}$.

(ii) If $s\left(h_{1}\right)=s\left(h_{2}\right)$, then

(a) if $\operatorname{env}\left(h_{1}\right)>\operatorname{env}\left(h_{2}\right)$, then $h_{1}$ is superior to $h_{2}$;

(b) if $\operatorname{env}\left(h_{1}\right)=\operatorname{env}\left(h_{2}\right)$, then $h_{1}, h_{2}$ represent the same information, denoted by $h_{1} \sim h_{2}$.

Let us take a simple example: for two HFLTSs $h_{1}=$ $\left\{s_{1}, s_{2}, s_{3}\right\}$ and $h_{2}=\left\{s_{2}, s_{3}\right\}$, by using the method proposed here, $s\left(h_{1}\right)<s\left(h_{2}\right)$, then $h_{1}<h_{2}$. The result is consistent with the result by using the envelope method proposed by Rodriguez et al. [32]. By using the envelope method for HFLTS, the envelopes of $h_{1}$ and $h_{2}$ are represented as $\operatorname{env}\left(h_{1}\right)=\left[s_{1}, s_{3}\right]$ and $\operatorname{env}\left(h_{2}\right)=\left[s_{2}, s_{3}\right]$, respectively. The comparison result is also consistent with human thinking in real life.

In order to highlight the generality of the method proposed in this paper, the methods to determine the ideal value for each criterion are represented as two generalized functions, denoted as $g$ - $\max (\cdot)$ for the positive-ideal value and $g-\min (\cdot)$ for the positive-ideal value, respectively. For example, in this paper, $g-\max (\cdot)$ or $g-\min (\cdot)$ is, respectively, used to return the biggest and smallest evaluation by the method proposed above operated on the hesitant fuzzy linguistic terms set.

The positive-ideal solutions are denoted as follows:

$$
\eta^{+}=\left(\eta_{1}^{+}, \eta_{2}^{+}, \ldots, \eta_{j}^{+}, \ldots, \eta_{n}^{+}\right), \quad j=1,2, \ldots, n,
$$

where $\eta_{j}^{+}=g-\max _{j}\left(p_{i j}\right)$ if $j \in C_{1}$ and $\eta_{j}^{+}=g-\min _{j}\left(p_{i j}\right)$ if $j \in C_{2}, i=1,2, \ldots, m, j=1,2, \ldots, n$.

The negative-ideal solutions are denoted as follows:

$$
\eta^{-}=\left(\eta_{1}^{-}, \eta_{2}^{-}, \ldots, \eta_{j}^{-}, \ldots, \eta_{n}^{-}\right), \quad j=1,2, \ldots, n,
$$

where $\eta_{j}^{-}=g-\min _{j}\left(p_{i j}\right)$ if $j \in C_{1}$ and $\eta_{j}^{-}=g-\max _{j}\left(p_{i j}\right)$ if $j \in C_{2}, i=1,2, \ldots, m, j=1,2, \ldots, n$.

Step 3. Use the proposed 2-tuple Choquet integral distance measures for collections of HFLTSs to compute the distance between alternative and the ideal or reference solution for each alternative. As an example, take the positive-ideal solution as reference solution

$$
\begin{aligned}
& \operatorname{CDHLS}_{\mu}\left(x_{i}, \eta^{+}\right)=\sum_{i=1}^{n}\left(\left(\frac{1}{L}\right.\right. \\
& \left.\cdot \sum_{l=1}^{L}\left|\frac{\Delta^{-1}\left(s_{\delta_{l}^{x_{i}}}, \alpha_{\delta_{l}^{x_{i}}}\right)-\Delta^{-1}\left(s_{\delta_{l}^{\eta^{+}}}, \alpha_{\delta_{l}^{\eta^{+}}}\right)}{g+1}\right|\right) \\
& \left.\cdot\left[\mu\left(C_{\sigma(i)}\right)-\mu\left(C_{\sigma(i+1)}\right)\right]\right),
\end{aligned}
$$

where $i=1,2, \ldots, m ; j=1,2, \ldots, n,(\sigma(1), \sigma(2), \ldots, \sigma(n))$ is a permutation of $(1,2, \ldots, n)$, so that $d_{\sigma(1)}\left(p_{i j}, \eta_{i j}^{+}\right) \leq$ $d_{\sigma(2)}\left(p_{i j}, \eta_{i j}^{+}\right) \leq \cdots \leq d_{\sigma(n)}\left(p_{i j}, \eta_{i j}^{+}\right), C_{\sigma(j)}=$ $\left\{c_{\sigma(j)}, c_{\sigma(j+1)}, \ldots, c_{\sigma(n)}\right\}, C_{\sigma(n+1)}=\phi$.

Step 4. Rank the alternatives based on the results of 2-tuple Choquet integral distance measures for collections of HFLTSs of each alternative.

\section{Application to Renewable Energy Projects Selection}

As introduction in the first section, the issue of renewable energy projects selection is a fuzzy multicriteria decisionmaking problem. Due to the development of technology, economy, and environment, research on this issue has a trend where more and more uncertain and fuzzy factors take into consideration the decision-making process, which results in hesitation for experts to give evaluations and the type of the evaluations may be more appropriate in form of HFLTS. And the multicriteria decision-making process is becoming much more complex in order to pursue a better balance of economic and social activities and environmental impact, of which the existence of interaction among criteria is of great possibility or unavoidable. 
TABLE 1: The decision matrix of candidate renewable energy projects.

\begin{tabular}{lcccc}
\hline & $c_{1}$ & $c_{2}$ & $c_{3}$ & \\
\hline$x_{1}$ & $\left\{s_{3}, s_{4}\right\}$ & $\left\{s_{3}, s_{4}, s_{5}\right\}$ & $\left\{s_{4}, s_{5}\right\}$ & $\left\{s_{4}\right.$ \\
$x_{2}$ & $\left\{s_{2}, s_{3}\right\}$ & $\left\{s_{3}, s_{4}\right\}$ & $\left\{s_{5}, s_{3}, s_{4}\right\}$ & $\left\{s_{4}, s_{5}\right\}$ \\
$x_{3}$ & $\left\{s_{2}, s_{3}, s_{4}\right\}$ & $\left\{s_{4}, s_{5}\right\}$ & $\left\{s_{4}, s_{5}, s_{6}\right\}$ & $\left\{s_{2}, s_{3}\right\}$ \\
$x_{4}$ & $\left\{s_{4}, s_{5}\right\}$ & $\left\{s_{5}, s_{6}\right\}$ & $\left\{s_{4}, s_{5}, s_{6}\right\}$ & $\left\{s_{3}, s_{4}\right\}$ \\
$x_{5}$ & $\left\{s_{3}, s_{4}, s_{5}\right\}$ & $\left\{s_{2}, s_{3}\right\}$ & $\left\{s_{3}, s_{4}\right\}$ & $\left\{s_{4}, s_{5}\right\}$ \\
$x_{6}$ & $\left\{s_{4}, s_{5}\right\}$ & $\left\{s_{4}, s_{5}\right\}$ & & $\left\{s_{3}, s_{4}, s_{5}\right\}$ \\
\hline
\end{tabular}

TABLE 2: The decision matrix transformed into the form of 2-tuple HFLTS.

\begin{tabular}{ccccc}
\hline & $c_{1}$ & $c_{2}$ & $c_{3}$ & $c_{4}$ \\
\hline$x_{1}$ & $\left\{\left(s_{3}, 0\right),\left(s_{4}, 0\right)\right\}$ & $\left\{\left(s_{3}, 0\right),\left(s_{4}, 0\right),\left(s_{5}, 0\right)\right\}$ & $\left\{\left(s_{4}, 0\right),\left(s_{5}, 0\right)\right\}$ & $\left\{\left(s_{4}, 0\right),\left(s_{5}, 0\right)\right\}$ \\
$x_{2}$ & $\left\{\left(s_{2}, 0\right),\left(s_{3}, 0\right)\right\}$ & $\left\{\left(s_{3}, 0\right),\left(s_{4}, 0\right)\right\}$ & $\left\{\left(s_{2}, 0\right),\left(s_{3}, 0\right),\left(s_{4}, 0\right)\right\}$ & $\left\{\left(s_{3}, 0\right),\left(s_{4}, 0\right),\left(s_{5}, 0\right)\right\}$ \\
$x_{3}$ & $\left\{\left(s_{2}, 0\right),\left(s_{3}, 0\right),\left(s_{4}, 0\right)\right\}$ & $\left\{\left(s_{2}, 0\right),\left(s_{3}, 0\right)\right\}$ & $\left\{\left(s_{4}, 0\right),\left(s_{5}, 0\right)\right\}$ & $\left\{\left(s_{2}, 0\right),\left(s_{3}, 0\right)\right\}$ \\
$x_{4}$ & $\left\{\left(s_{4}, 0\right),\left(s_{5}, 0\right)\right\}$ & $\left\{\left(s_{5}, 0\right),\left(s_{6}, 0\right)\right\}$ & $\left\{\left(s_{4}, 0\right),\left(s_{5}, 0\right),\left(s_{6}, 0\right)\right\}$ & $\left\{\left(s_{3}, 0\right),\left(s_{4}, 0\right)\right\}$ \\
$x_{5}$ & $\left\{\left(s_{3}, 0\right),\left(s_{4}, 0\right),\left(s_{5}, 0\right)\right\}$ & $\left\{\left(s_{2}, 0\right),\left(s_{3}, 0\right)\right\}$ & $\left\{\left(s_{4}, 0\right),\left(s_{5}, 0\right),\left(s_{6}, 0\right)\right\}$ & $\left\{\left(s_{3}, 0\right),\left(s_{4}, 0\right)\right\}$ \\
$x_{6}$ & $\left\{\left(s_{4}, 0\right),\left(s_{5}, 0\right)\right\}$ & $\left\{\left(s_{4}, 0\right),\left(s_{5}, 0\right)\right\}$ & $\left\{\left(s_{3}, 0\right),\left(s_{4}, 0\right),\left(s_{5}, 0\right)\right\}$ \\
\hline
\end{tabular}

Here, for the evaluation of the renewable energy projects, we consider a highly ambiguous situation; the experts are allowed to give the evaluation values of each alternative on criteria in the form of the hesitant fuzzy linguistic terms set, and a decision model which is able to handle the interaction factors among criteria is established. In this section, we apply the proposed method in Section 4 to the evaluation of renewable energy projects and use an example to further validate the rationality of the proposed method in this paper. We will make a comparison analysis on the proposed MCDM method based on the 2-tuple Choquet integral distance measures for collections of HFLTSs with the hesitant fuzzy linguistic TOPSIS and the hesitant fuzzy linguistic VIKOR.

The numerical example is described as follows.

A local government is going to select the most competent renewable energy projects from four candidate projects. Because of the complexity of the new energy project system, high uncertainty of the application prospect, and the fuzziness of the expert cognition, evaluations values are required to be given in form of HFLTS. Suppose the basic linguistic terms set $S=\left\{s_{0}, \ldots, s_{6}\right\}$, of which $s_{0}$ is nothing, $s_{1}$ is very low, $s_{2}$ is low, $s_{3}$ is medium, $s_{4}$ is high, $s_{5}$ is very high, and $s_{6}$ is perfect. The candidate renewable energy projects are denoted as $X=\left\{x_{1}, x_{2}, x_{3}, x_{4}, x_{5}, x_{6}\right\}$. The criteria set used to evaluate performance of the renewable energy projects comes from the literature of [1]. Several criteria are chosen by the decision makers to compose the criteria set, which is denoted as $C=\left\{c_{1}, c_{2}, c_{3}, c_{4}\right\}$. The criteria are represented as follows: $c_{1}$ is technical maturity degree; $c_{2}$ is ecological impact level; $c_{3}$ is service life level; $c_{4}$ is social acceptability degree.

The procedure to select the most competent renewable energy project based on 2-tuple Choquet integral distance measures for collections of HFLTSs is as follows.

Step 1. Make up the decision matrix for renewable energy projects with hesitant fuzzy linguistic terms set with respect to the four evaluating criteria according to the experts' judgments. Based on the hesitant fuzzy linguistic judgments on the alternatives, the decision matrix of candidate renewable energy projects is obtained as in Table 1.

In order to apply the proposed 2-tuple Choquet integral distance measures for collections of HFLTSs, here, we transfer the original decision matrix into the form of 2-tuple HFLTS, which is shown in Table 2.

Step 2. Confirm the fuzzy measures on criteria set $C$ and the subsets of $C$ by using the fuzzy measure methods mentioned in the previous section. Suppose the fuzzy measures are as follows:

$$
\begin{aligned}
\mu\left(c_{1}\right) & =0.40, \\
\mu\left(c_{2}\right) & =0.25, \\
\mu\left(c_{3}\right) & =0.37, \\
\mu\left(c_{4}\right) & =0.20, \\
\mu\left(c_{1}, c_{2}\right) & =0.76, \\
\mu\left(c_{1}, c_{3}\right) & =0.65, \\
\mu\left(c_{1}, c_{4}\right) & =0.61, \\
\mu\left(c_{2}, c_{3}\right) & =0.45, \\
\mu\left(c_{2}, c_{4}\right) & =0.34, \\
\mu\left(c_{3}, c_{4}\right) & =0.42, \\
\mu\left(c_{1}, c_{2}, c_{3}\right) & =0.85, \\
\mu\left(c_{1}, c_{2}, c_{4}\right) & =0.68, \\
\mu\left(c_{1}, c_{3}, c_{4}\right) & =0.76, \\
\mu\left(c_{2}, c_{3}, c_{4}\right) & =0.57, \\
\mu\left(c_{1}, c_{2}, c_{3}, c_{4}\right) & =1.0 .
\end{aligned}
$$


Step 3. Determine the positive-ideal solution $\eta^{+}=\left(\eta_{1}^{+}, \eta_{2}^{+}\right.$, $\left.\ldots, \eta_{n}^{+}\right)$, by using the comparison method for HFLTSs proposed in Section 4.

By using the comparison method, we get the positive-ideal solution: $\eta^{+}=\left(\eta_{1}^{+}, \eta_{2}^{+}, \ldots, \eta_{n}^{+}\right)=\left(\left\{s_{4}, s_{5}\right\},\left\{s_{2}, s_{3}\right\}\right.$, $\left.\left\{s_{4}, s_{5}, s_{6}\right\},\left\{s_{4}, s_{5}\right\}\right)$

Step 4. Compute the distances between alternative and the ideal solution for each alternative by using the 2-tuple Choquet integral distance measures for collections of HFLTSs; suppose the decision maker is optimistic; the results are as follows:

$$
\begin{aligned}
& c d_{1}=0.0787, \\
& c d_{2}=0.2216, \\
& c d_{3}=0.1095, \\
& c d_{4}=0.1739, \\
& c d_{5}=0.2109, \\
& c d_{6}=0.0998 .
\end{aligned}
$$

Take the candidate $x_{1}$ as an example; the computation process for the 2-tuple Choquet integral distance between $x_{1}$ and positive-ideal solution is as follows.

For

$$
\begin{aligned}
d\left(p_{11}, \eta_{11}^{+}\right) & =\frac{1}{7}, \\
d\left(p_{12}, \eta_{12}^{+}\right) & =\frac{1}{19}, \\
d\left(p_{13}, \eta_{13}^{+}\right) & =\frac{1}{21}, \\
d\left(p_{14}, \eta_{14}^{+}\right) & =0, \\
d_{\sigma(1)}\left(p_{14}, \eta_{14}^{+}\right) & <d_{\sigma(2)}\left(p_{12}, \eta_{12}^{+}\right)<d_{\sigma(3)}\left(p_{13}, \eta_{13}^{+}\right) \\
& <d_{\sigma(4)}\left(p_{11}, \eta_{11}^{+}\right),
\end{aligned}
$$

then, we get $\mu_{\sigma(1)}=\mu\left\{c_{1}, c_{2}, c_{3}, c_{4}\right\}=1, \mu_{\sigma(2)}=\mu\left\{c_{1}, c_{2}, c_{3}\right\}=$ $0.85, \mu_{\sigma(3)}=\mu\left\{c_{1}, c_{3}\right\}=0.65, \mu_{\sigma(4)}=\mu\left\{c_{1}\right\}=0.40$,

$$
\begin{aligned}
& \operatorname{CDHLS}_{\mu}(\widetilde{A}, \widetilde{B})=\sum_{i=1}^{n}\left(\left(\frac{1}{L}\right.\right. \\
& \left.\cdot \sum_{l=1}^{L}\left|\frac{\Delta^{-1}\left(s_{\delta_{l}^{\tilde{a}_{\sigma(i)}}}, \alpha_{\delta_{l}^{\tilde{a}_{\sigma(i)}}}\right)-\Delta^{-1}\left(s_{\delta_{l}^{\tilde{b}_{\sigma(i)}}}, \alpha_{\delta_{l}^{\tilde{b}_{\sigma(i)}}}\right)}{g+1}\right|\right) \\
& \cdot\left[\mu\left(C_{\sigma(i)}\right)-\mu\left(C_{\sigma(i+1)}\right)\right] .
\end{aligned}
$$

So,

$$
\begin{aligned}
c d_{1}= & \operatorname{CDHLS}_{\mu}\left(x_{1}, \eta^{+}\right) \\
= & 0 \times(1-0.85)+\frac{(0.85-0.65)}{21}+\frac{(0.65-0.40)}{19} \\
& +\frac{(0.4-0)}{7}=0.0787 .
\end{aligned}
$$

Step 5. Rank the alternatives based on the results of the 2tuple Choquet integral distance measures for collections of HFLTSs to get the most suitable renewable energy project.

Because $c d_{1}<c d_{6}<c d_{3}<c d_{4}<c d_{5}<c d_{2}$, the candidate $x_{1}$ has the nearest distance from the positive-ideal solution; hence the renewable energy project $x_{1}$ is the most suitable renewable energy project.

In order to illustrate the validity and practicability of the proposed method, we firstly compare our proposed method with the generalized interval-valued hesitant fuzzy linguistic Shapley Choquet integral operator, which handles the interaction among hesitant fuzzy linguistic numbers from the perspective of information fusion [80]. Then comparisons with the hesitant fuzzy linguistic TOPSIS and hesitant fuzzy linguistic VIKOR are also made to highlight the ability of the proposed method in dealing with the interactions among criteria in hesitant fuzzy linguistic situation from the perspective of distance measure.

Comparison Analysis. As described in the first part, because of the characteristic of HFLTS, an evaluation value containing several fuzzy elements, to our knowledge until now, very little work has been done about the MCDM problem in hesitant linguistic context considering the existence of interaction among criteria from the perspective of information aggregation. There is no quite suitable case in the existing literatures within our capability that can be used to make a comparison with the method proposed here. However, the hesitant fuzzy linguistic numbers can be seen as one particular formation of the generalized interval-valued hesitant fuzzy linguistic numbers. So we can make a comparison between our proposed method with the generalized interval-valued hesitant fuzzy linguistic Shapley Choquet integral operator [80].

Suppose they have the same fuzzy measure; then we apply the method in paper [80] to the previous example. The computation results are as follows.

By using the generalized interval-valued hesitant fuzzy linguistic Choquet integral (G-IVHFLCOA) proposed in paper [80], we get

$$
\begin{aligned}
& \text { G-IVHFlCOA }\left(x_{1}\right)=\left\{s_{4.1}, s_{4.7}, s_{5.3}\right\}, \\
& \text { G-IVHFlCOA }\left(x_{2}\right)=\left\{s_{2.4}, s_{3.1}, s_{3.6}\right\}, \\
& \text { G-IVHFlCOA }\left(x_{3}\right)=\left\{s_{3.7}, s_{4.5}, s_{5.1}\right\}, \\
& \text { G-IVHFlCOA }\left(x_{4}\right)=\left\{s_{3.5}, s_{4.1}, s_{4.8}\right\}, \\
& \text { G-IVHFLCOA }\left(x_{5}\right)=\left\{s_{2.7}, s_{3.9}, s_{4.0}\right\}, \\
& \text { G-IVHFLCOA }\left(x_{6}\right)=\left\{s_{3.9}, s_{4.6}, s_{5.1}\right\} .
\end{aligned}
$$


TABLE 3

\begin{tabular}{lcccccc}
\hline$i$ & 1 & 2 & 3 & 4 & 5 & 6 \\
$S_{i}$ & 0.093 & 0.599 & 0.425 & 0.598 & 0.691 & 0.464 \\
$R_{i}$ & 0.155 & 0.198 & 0.199 & 0.364 & 0.207 & 0.139 \\
$Q_{i}$ & 0.166 & 0.379 & 0.461 & 0.229 & 0.301 & 0.191 \\
\hline
\end{tabular}

TABLE 4: Ranking results by several methods operating on the illustrative example.

\begin{tabular}{lr}
\hline Methods & Ranking results \\
\hline Method proposed in this paper & $x_{1}>x_{6}>x_{3}>x_{4}>x_{5}>x_{2}$ \\
\hline G- IVHFLCOA & $x_{1}>x_{6}>x_{3}>x_{4}>x_{5}>x_{2}$ \\
Hesitant fuzzy linguistic TOPSIS & $x_{6}>x_{1}>x_{4}>x_{3}>x_{5}>x_{2}$ \\
Hesitant fuzzy linguistic VIKOR & $x_{1}>x_{6}>x_{4}>x_{5}>x_{2}>x_{3}$ \\
\hline
\end{tabular}

By using the comparison rules for hesitant fuzzy linguistic numbers in Section 4 we have the following.

For a HFLTS $h, s(h)=(1 / l(h)) \sum_{\gamma \in h} \Delta^{-1}(\gamma)$ is the score function of $h$, where $l(h)$ is the number of elements in $h$ and $\Delta^{-1}(\cdot)$ is the 2-tuple linguistic transfer function.

The scores are as follows:

$$
\begin{aligned}
& s\left(x_{1}\right)=4.70, \\
& s\left(x_{2}\right)=3.03, \\
& s\left(x_{3}\right)=4.43, \\
& s\left(x_{4}\right)=4.13, \\
& s\left(x_{5}\right)=3.53, \\
& s\left(x_{6}\right)=4.53 .
\end{aligned}
$$

The ranking result is as follows:

$s\left(x_{1}\right)>s\left(x_{6}\right)>s\left(x_{3}\right)>s\left(x_{4}\right)>s\left(x_{5}\right)>s\left(x_{2}\right)$.

The result is consistent with the result of our proposed method.

What is more, suppose the four criteria have the same weight; then we have the following.

By using the TOPSIS method for hesitant fuzzy linguistic terms set proposed by Beg and Rashid [34], we get the ranking result as follows:

$$
x_{6}>x_{1}>x_{4}>x_{3}>x_{5}>x_{2} .
$$

The relative closeness $\mathrm{RC}\left(x_{1}\right)$ to the ideal solution by hesitant fuzzy linguistic TOPSIS is as follows:

$$
\begin{aligned}
& \operatorname{RC}\left(x_{1}\right)=0.209, \\
& \operatorname{RC}\left(x_{2}\right)=0.629, \\
& \operatorname{RC}\left(x_{3}\right)=0.437, \\
& \operatorname{RC}\left(x_{4}\right)=0.311, \\
& \operatorname{RC}\left(x_{5}\right)=0.533, \\
& \operatorname{RC}\left(x_{6}\right)=0.133 .
\end{aligned}
$$

And by using the hesitant fuzzy linguistic VIKOR method for hesitant fuzzy linguistic terms set proposed by Liao et al. [39], we get the ranking result as follows:

$$
x_{1}>x_{6}>x_{4}>x_{5}>x_{2}>x_{3} .
$$

The detailed computation results by the hesitant fuzzy linguistic VIKORare shown in Table 3.

The result by G-IVHFLCOA is consistent with the result of our proposed method. This consistency proves the correctness and reasonableness of the method we propose. Compared with the G-IVHFLCOA method, our proposed method provides another way to solve this problem considering the interaction among criteria in hesitant fuzzy linguistic situation from the perspective of distance measure. It is more suitable and reliable for multicriteria decisionmaking with hesitant fuzzy linguistic information, because it is more difficult to aggregate the hesitant fuzzy linguistic numbers for its characteristic of composed of several linguistic terms, especially when the interaction among criteria are considered. Compared with the G-IVHFLCOA method, our proposed method can be more intuitive to reflect the merits of the decision-making results from the perspective of distance measure. As for the differences between the ranking results by using the proposed method, the hesitant fuzzy linguistic TOPSIS, and the hesitant fuzzy linguistic VIKOR, that is because the method proposed in this paper takes into consideration the interaction among criteria. The hesitant fuzzy linguistic TOPSIS and the hesitant fuzzy linguistic VIKOR method cannot take into consideration the interaction among criteria. However, in this example, there are interactions among criteria; for example, there is positive interaction among $c_{1}$, technical maturity degree, and $\mathrm{c}_{4}$, social acceptability degree. High technical maturity degree is bound to bring high social acceptability degree, which leads to small distance to the positive ideal solution than that disregarding the interactions among criteria. Take the position of $\mathrm{x} 1$ and $\mathrm{x} 6$ in the ranking results as example, from the fuzzy measure about the criteria set given above, we can find that there are positive interactions between these two criteria. So when the interaction is considered, the method proposed here can lead to smaller distance than that by using the hesitant fuzzy linguistic TOPSIS and the hesitant 
fuzzy linguistic VIKOR. Then different ranking results are obtained.

Renewable energy planning is an important part of the development of renewable energy, and decision-making for renewable energy projects selection is a complex problem with multiple criteria considering all the technical, economic, social, and environmental factors. What is more, to develop renewable energy is to pursue a balance of economic and social activities and environment, of which the existence of interaction among criteria is of great possibility. Managers are pursuing high-quality decision-making to meet the needs of production and life in the field of renewable energy. In practice, because of the novelty of new energy technologies, high uncertainty of situation and limited cognition of human thinking should be considered. According to the available information and the experts' expertise in new energy management, the decision makers cannot choose only one linguistic evaluation value from the established linguistic terms set to represent his judgment in some situation. The method proposed in this paper can take into consideration much more uncertain and fuzzy factors, and decision makers are allowed to express their preference in a set of several objects with corresponding degrees of hesitation in renewable energy projects evaluation. The interactions among criteria are also handling approximately. It can reduce the decision pressure and improve the renewable energy projects selection decision-making efficiency because the decision maker are allowed to express their preference in form of HFLTS and a decision criteria set of which the criteria are independent with each other is not necessary. Compared to the relevant existing methods, method proposed here can be more intuitive to reflect the merits of the renewable energy projects selection decision results.

\section{Conclusions}

Renewable energy projects selection is a multicriteria decision-making problem considering all the technical, economic, social, and environmental factors, of which the existence of interaction among criteria is of great possibility, sometimes inevitable. For the evaluation of the performance of renewable energy projects, we consider a highly ambiguous situation, where the experts are allowed to give the evaluation values in the form of the hesitant fuzzy linguistic terms set. A decision-making model handling the interaction among criteria from the perspective of distance measure by using the 2-tuple linguistic representation approach and discrete Choquet integral is established. Several discrete Choquet integral distance measures modeling the interacting criteria from the perspective of distance measure are defined for collections of HFLTSs. Compared to the existing methods for evaluation of the performance of renewable energy projects, the method proposed here can take into consideration more fuzzy information and deal with the interaction among criteria more approximately. This method can reduce the decision pressure and improve the decision-making efficiency because the decision maker is allowed to represent their preference in form of HFLTS and a decision criteria set of which the criteria are independent of each other is not necessary. Besides, compared to the G-IVHFLCOA method, method proposed here can be more intuitive to reflect the merits of the decisionmaking results from the perspective of distance measure.

For further research, distance measure between fuzzy sets, especially the collection of HFLTSs, should be continuously improved and optimized to carry more information in order to reflect the preference fully of the decision makers and the decision situation of renewable energy panning. And the classical MCDM techniques based on distance measure, such as TOPSIS and VIKOR, can be integrated with more fuzzy information to assess the renewable energy projects more scientifically and reasonably in some particular fuzzy situations.

\section{Conflicts of Interest}

The authors declare that there are no conflicts of interest regarding the publication of this paper.

\section{References}

[1] J. Wang, Y. Jing, C. Zhang, and J. Zhao, "Review on multicriteria decision analysis aid in sustainable energy decisionmaking," Renewable Sustainable Energy Reviews, vol. 13, no. 9, pp. 2263-2278, 2009.

[2] E. Loken, "Use of multicriteria decision analysis methods for energy planning problems," Renewable \& Sustainable Energy Reviews, vol. 11, no. 7, pp. 1584-1595, 2007.

[3] H. Polatidis, D. A. Haralambopoulos, G. Munda, and R. Vreeker, "Selecting an appropriate multi-criteria decision analysis technique for renewable energy planning," Energy Sources, Part B: Economics, Planning, and Policy, vol. 1, no. 2, pp. 181-193, 2006.

[4] S. D. Pohekar and M. Ramachandran, "Application of multicriteria decision making to sustainable energy planning-a review," Renewable \& Sustainable Energy Reviews, vol. 8, no. 4, pp. 365-381, 2004.

[5] D. A. Haralambopoulos and H. Polatidis, "Renewable energy projects: Structuring a multi-criteria group decision-making framework," Journal of Renewable Energy, vol. 28, no. 6, pp. 961973, 2003.

[6] M. Beccali, M. Cellura, and M. Mistretta, "Decision-making in energy planning. Application of the Electre method at regional level for the diffusion of renewable energy technology," Journal of Renewable Energy, vol. 28, no. 13, pp. 2063-2087, 2003.

[7] E. Strantzali and K. Aravossis, "Decision making in renewable energy investments: A review," Renewable \& Sustainable Energy Reviews, vol. 55, pp. 885-898, 2016.

[8] M. Saeedpoor and A. Vafadarnikjoo, "Multicriteria renewable energy planning using an integrated fuzzy vikor \&amp; ahp methodology: the case of istanbul," Energy, vol. 79, pp. 536-537, 2015.

[9] A. Yazdani-Chamzini, M. M. Fouladgar, E. K. Zavadskas, and S. H. H. Moini, "Selecting the optimal renewable energy using multi criteria decision making," Journal of Business Economics and Management, vol. 14, no. 5, pp. 957-978, 2013.

[10] L. Balezentiene, D. Streimikiene, and T. Balezentis, "Fuzzy decision support methodology for sustainable energy crop selection," Renewable \& Sustainable Energy Reviews, vol. 17, pp. 83-93, 2013. 
[11] T. Ertay, C. Kahraman, and I. Kaya, "Evaluation of renewable energy alternatives using MACBETH and fuzzy AHP multicriteria methods: the case of Turkey," Technological and Economic Development of Economy, vol. 19, no. 1, pp. 38-62, 2013.

[12] T. Kaya and C. Kahraman, "Multicriteria decision making in energy planning using a modified fuzzy TOPSIS methodology," Expert Systems with Applications, vol. 38, no. 6, pp. 6577-6585, 2011.

[13] J. San Cristóbal, "Multi-criteria decision-making in the selection of a renewable energy project in spain: the Vikor method," Journal of Renewable Energy, vol. 36, no. 2, pp. 498-502, 2011.

[14] C. Kahraman, I. Kaya, and S. Cebi, "A comparative analysis for multiattribute selection among renewable energy alternatives using fuzzy axiomatic design and fuzzy analytic hierarchy process," Energy, vol. 34, no. 10, pp. 1603-1616, 2009.

[15] A. I. AbdelAzim, A. M. Ibrahim, and E. M. Aboul-Zahab, "Development of an energy efficiency rating system for existing buildings using Analytic Hierarchy Process-the case of Egypt," Renewable \& Sustainable Energy Reviews, vol. 71, pp. 414-425, 2017.

[16] A. Balin and H. Baraçli, "A fuzzy multi-criteria decision making methodology based upon the interval type-2 fuzzy sets for evaluating renewable energy alternatives in Turkey," Technological and Economic Development of Economy, 2015.

[17] M. M. Abaei, E. Arzaghi, R. Abbassi, V. Garaniya, and I. Penesis, "Developing a novel risk-based methodology for multi-criteria decision making in marine renewable energy applications," Journal of Renewable Energy, vol. 102, pp. 341-348, 2017.

[18] Y. Çelikbilek and F. Tüysüz, "An integrated grey based multicriteria decision making approach for the evaluation of renewable energy sources," Energy, vol. 115, pp. 1246-1258, 2016.

[19] C. Bhowmik, S. Bhowmik, A. Ray, and K. M. Pandey, "Optimal green energy planning for sustainable development: A review," Renewable \& Sustainable Energy Reviews, vol. 71, pp. 796-813, 2017.

[20] T. Wu, D. L. Xu, and J. B. Yang, "A review on multiple criteria performance analysis of renewable energy systems," in Proceedings of the IEEE International Conference on Control Automation, pp. 822-827, IEEE, 2017.

[21] A. Kumar, B. Sah, A. R. Singh et al., "A review of multi criteria decision making (MCDM) towards sustainable renewable energy development," Renewable \& Sustainable Energy Reviews, vol. 69, pp. 596-609, 2017.

[22] M. E. Arce, A. Saavedra, J. L. Míguez, and E. Granada, “The use of grey-based methods in multi-criteria decision analysis for the evaluation of sustainable energy systems: a review," Renewable \& Sustainable Energy Reviews, vol. 47, pp. 924-932, 2015.

[23] I. Dincer and C. Acar, "A review on clean energy solutions for better sustainability," International Journal of Energy Research, vol. 39, no. 5, pp. 585-606, 2015.

[24] S. Zeng, D. Streimikiene, and T. Baležentis, "Review of and comparative assessment of energy security in Baltic States," Renewable \& Sustainable Energy Reviews, vol. 76, pp. 185-192, 2017.

[25] V. Torra, "Hesitant fuzzy sets," International Journal of Intelligent Systems, vol. 25, no. 6, pp. 529-539, 2010.

[26] M. Xia and Z. Xu, "Hesitant fuzzy information aggregation in decision making," International Journal of Approximate Reasoning, vol. 52, no. 3, pp. 395-407, 2011.

[27] Z. Xu and M. Xia, "Distance and similarity measures for hesitant fuzzy sets," Information Sciences, vol. 181, no. 11, pp. 2128-2138, 2011.
[28] Z. Xu and X. Zhang, "Hesitant fuzzy multi-attribute decision making based on TOPSIS with incomplete weight information," Knowledge-Based Systems, vol. 52, pp. 53-64, 2013.

[29] M. Xia, Z. Xu, and N. Chen, "Some hesitant fuzzy aggregation operators with their application in group decision making," Group Decision and Negotiation, vol. 22, no. 2, pp. 259-279, 2013.

[30] N. Zhang and G. Wei, "Extension of VIKOR method for decision making problem based on hesitant fuzzy set," Applied Mathematical Modelling, vol. 37, no. 7, pp. 4938-4947, 2013.

[31] D. Joshi and S. Kumar, "Interval-valued intuitionistic hesitant fuzzy Choquet integral based TOPSIS method for multi-criteria group decision making," European Journal of Operational Research, vol. 248, no. 1, pp. 183-191, 2016.

[32] R. M. Rodriguez, L. Martinez, and F. Herrera, "Hesitant fuzzy linguistic term sets for decision making," IEEE Transactions on Fuzzy Systems, vol. 20, no. 1, pp. 109-119, 2012.

[33] R. M. Rodríguez, L. Martínez, and F. Herrera, "A group decision making model dealing with comparative linguistic expressions based on hesitant fuzzy linguistic term sets," Information Sciences, vol. 241, pp. 28-42, 2013.

[34] I. Beg and T. Rashid, "TOPSIS for hesitant fuzzy linguistic term sets," International Journal of Intelligent Systems, vol. 28, no. 12, pp. 1162-1171, 2013.

[35] C. Wei, N. Zhao, and X. Tang, "Operators and comparisons of hesitant fuzzy linguistic term sets," IEEE Transactions on Fuzzy Systems, vol. 22, no. 3, pp. 575-585, 2014.

[36] Z. Zhang and C. Wu, "Hesitant fuzzy linguistic aggregation operators and their applications to multiple attribute group decision making," Journal of Intelligent \& Fuzzy Systems. Applications in Engineering and Technology, vol. 26, no. 5, pp. 21852202, 2014.

[37] H. Liao, Z. Xu, and X. J. Zeng, "Distance and similarity measures for hesitant fuzzy linguistic term sets and their application in multi-criteria decision making," Information Sciences, vol. 271, pp. 125-142, 2014.

[38] H. Liu and R. M. Rodríguez, "A fuzzy envelope for hesitant fuzzy linguistic term set and its application to multicriteria decision making," Information Sciences, vol. 258, pp. 220-238, 2014.

[39] H. Liao, Z. Xu, and X.-J. Zeng, "Hesitant Fuzzy Linguistic VIKOR Method and Its Application in Qualitative Multiple Criteria Decision Making," IEEE Transactions on Fuzzy Systems, vol. 23, no. 5, pp. 1343-1355, 2015.

[40] B. Farhadinia, "Multiple criteria decision-making methods with completely unknown weights in hesitant fuzzy linguistic term setting," Knowledge-Based Systems, vol. 93, pp. 135-144, 2016.

[41] X. Gou, Z. Xu, and H. Liao, "Hesitant fuzzy linguistic entropy and cross-entropy measures and alternative queuing method for multiple criteria decision making," Information Sciences, vol. 388-389, pp. 225-246, 2017.

[42] S. Yu, H. Zhang, and J. Wang, "Hesitant Fuzzy Linguistic Maclaurin Symmetric Mean Operators and their Applications to Multi-Criteria Decision-Making Problem," International Journal of Intelligent Systems, 2017.

[43] G. Wei, "Interval-valued dual hesitant fuzzy uncertain linguistic aggregation operators in multiple attribute decision making," Iranian Journal of Fuzzy Systems, vol. 33, no. 3, pp. 1881-1893, 2017.

[44] Z. S. Xu, L. Pan, and H. C. Liao, "Multi-criteria decision making method of hesitant fuzzy linguistic term set based on improved MACBETH method," Kongzhi yu Juece/Control and Decision, vol. 32, no. 7, pp. 1266-1272, 2017. 
[45] H. Liao, X. Gou, and Z. Xu, "A survey of decision making theory and methodologies of hesitant fuzzy linguistic term set," Xitong Gongcheng Lilun yu Shijian/System Engineering Theory and Practice, vol. 37, no. 1, pp. 35-48, 2017.

[46] Y. Xu, A. Xu, J. M. Merigó, and H. Wang, "Hesitant fuzzy linguistic ordered weighted distance operators for group decision making," Journal of Applied Mathematics and Computing, vol. 49, no. 1-2, pp. 285-308, 2015.

[47] F. Meng and X. Chen, "A hesitant fuzzy linguistic multigranularity decision making model based on distance measures," Journal of Intelligent \& Fuzzy Systems: Applications in Engineering and Technology, vol. 28, no. 4, pp. 1519-1531, 2015.

[48] H. Liao and Z. Xu, "Approaches to manage hesitant fuzzy linguistic information based on the cosine distance and similarity measures for HFLTSs and their application in qualitative decision making," Expert Systems with Applications, vol. 42, no. 12, pp. 5328-5336, 2015.

[49] Y. Pang and W. Yang, "Some hesitant intuitionistic fuzzy linguistic distance measures," International Journal of Innovative Computing, Information and Control, vol. 11, no. 5, pp. 15731586, 2015.

[50] H.-C. Huang and X. Yang, "Pairwise Comparison and Distance Measure of Hesitant Fuzzy Linguistic Term Sets," Mathematical Problems in Engineering, vol. 2014, Article ID 954040, 2014.

[51] J.-Q. Wang, J.-T. Wu, J. Wang, H.-Y. Zhang, and X.-H. Chen, "Multi-criteria decision-making methods based on the Hausdorff distance of hesitant fuzzy linguistic numbers," Soft Computing, 2015.

[52] C. Wei, Z. Ren, and R. M. Rodríguez, "A hesitant fuzzy linguistic TODIM method based on a score function," International Journal of Computational Intelligence Systems, vol. 8, no. 4, pp. 701-712, 2015.

[53] P. Liu, S.-M. Chen, and J. Liu, "Multiple attribute group decision making based on intuitionistic fuzzy interaction partitioned Bonferroni mean operators," Information Sciences, vol. 411, pp. 98-121, 2017.

[54] R. Lourenzutti, R. A. Krohling, and M. Z. Reformat, "Choquet based TOPSIS and TODIM for dynamic and heterogeneous decision making with criteria interaction," Information Sciences, vol. 408, pp. 41-69, 2017.

[55] W. F. Liu, Y. X. Du, and J. Chang, "Pythagorean fuzzy interaction aggregation operators and applications in decision making," Kongzhi yu Juece/Control and Decision, vol. 32, no. 6, pp. 10331040, 2017.

[56] Y. D. He, Z. He, and H. Huang, "Decision making with the generalized intuitionistic fuzzy power interaction averaging operators," Soft Computing, 2015.

[57] G. Wei, "Pythagorean fuzzy interaction aggregation operators and their application to multiple attribute decision making," Journal of Intelligent \& Fuzzy Systems: Applications in Engineering and Technology, vol. 33, no. 4, pp. 2119-2132, 2017.

[58] H. Garg, "Generalized intuitionistic fuzzy interactive geometric interaction operators using Einstein t-norm and t-conorm and their application to decision making," Computers \& Industrial Engineering, vol. 101, pp. 53-69, 2016.

[59] S.-M. Chen and J.-A. Hong, "Multicriteria linguistic decision making based on hesitant fuzzy linguistic term sets and the aggregation of fuzzy sets," Information Sciences, vol. 286, pp. 6374, 2014.

[60] Z. Xu and J. Chen, "Ordered weighted distance measure," Journal of Systems Science and Systems Engineering, vol. 17, no. 4, pp. 432-445, 2008.
[61] S. Zeng, J. M. Merigó, D. Palacios-Marqués, H. Jin, and F. Gu, "Intuitionistic fuzzy induced ordered weighted averaging distance operator and its application to decision making," Journal of Intelligent \& Fuzzy Systems: Applications in Engineering and Technology, vol. 32, no. 1, pp. 11-22, 2017.

[62] Z. Shouzhen, "An Extension of OWAD Operator and Its Application to Uncertain Multiple-Attribute Group DecisionMaking," Cybernetics and Systems, vol. 47, no. 5, pp. 363-375, 2016.

[63] J. M. Merigó and M. Casanovas, "Decision-making with distance measures and induced aggregation operators," Computers \& Industrial Engineering, vol. 60, no. 1, pp. 66-76, 2011.

[64] J. M. Merigó and M. Casanovas, "Induced aggregation operators in the Euclidean distance and its application in financial decision making," Expert Systems with Applications, vol. 38, no. 6, pp. 7603-7608, 2011.

[65] S. Zeng and W. Su, "Intuitionistic fuzzy ordered weighted distance operator," Knowledge-Based Systems, vol. 24, no. 8, pp. 1224-1232, 2011.

[66] T. Murofushi and M. Sugeno, "An interpretation of fuzzy measures and the Choquet integral as an integral with respect to a fuzzy measure," Fuzzy Sets and Systems, vol. 29, no. 2, pp. 201-227, 1989.

[67] J.-L. Marichal, "An axiomatic approach of the discrete Choquet integral as a tool to aggregate interacting criteria," IEEE Transactions on Fuzzy Systems, vol. 8, no. 6, pp. 800-807, 2000.

[68] H. Liao, Z. Xu, and X. Zeng, "Distance and similarity measures for hesitant fuzzy linguistic term sets and their application in multi-criteria decision making," Information Sciences, vol. 271, pp. 125-142, 2014.

[69] N. B. Karayiannis, "Soft learning vector quantization and clustering algorithms based on ordered weighted aggregation operators," IEEE Transactions on Neural Networks and Learning Systems, vol. 11, no. 5, pp. 1093-1105, 2000.

[70] X. U. Zeshui and J. Chen, “Ordered weighted distance measure," Journal of Systems Science and Systems Engineering, vol. 17, no. 4, pp. 432-445, 2008.

[71] V. Torra, "On the construction of models based on fuzzy measures and integrals," Studies in Fuzziness and Soft Computing, vol. 220, pp. 89-97, 2008.

[72] M. Grabisch and C. Labreuche, "A decade of application of the Choquet and Sugeno integrals in multi-criteria decision aid," Annals of Operations Research, vol. 175, pp. 247-286, 2010.

[73] A. Keikha and H. Mishmast Nehi, "Fuzzified Choquet Integral and its Applications in MADM: A Review and A New Method," International Journal of Fuzzy Systems, vol. 17, no. 2, pp. 337-352, 2015.

[74] F. Herrera and L. Martínez, "A 2-tuple fuzzy linguistic representation model for computing with words," IEEE Transactions on Fuzzy Systems, vol. 8, no. 6, pp. 746-752, 2000.

[75] Z. S. Xu, "Deviation measures of linguistic preference relations in group decision making," Omega, vol. 33, no. 3, pp. 249-254, 2005.

[76] M. Grabisch, "A new algorithm for identifying fuzzy measures and its application to pattern recognition," in Proceedings of the IEEE International Conference on Fuzzy Systems \& International fuzzy Engineering Symposium, vol. 1, pp. 145-150, 1995.

[77] M. Grabisch, "The application of fuzzy integrals in multicriteria decision making," European Journal of Operational Research, vol. 89, no. 3, pp. 445-456, 1996. 
[78] W. Wang, Z. Wang, and G. J. Klir, "Genetic algorithms for determining fuzzy measures from data," Journal of Intelligent \& Fuzzy Systems: Applications in Engineering and Technology, vol. 6, no. 2, pp. 171-183, 1998.

[79] M. Larbani, C.-Y. Huang, and G.-H. Tzeng, "A novel method for fuzzy measure identification," International Journal of Fuzzy Systems, vol. 13, no. 1, pp. 24-34, 2011.

[80] W. Zhang, Y. Ju, and X. Liu, "Multiple criteria decision analysis based on Shapley fuzzy measures and interval-valued hesitant fuzzy linguistic numbers," Computers \& Industrial Engineering, vol. 105, pp. 28-38, 2017. 


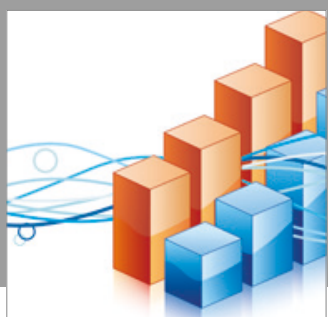

Advances in

Operations Research

vatersals

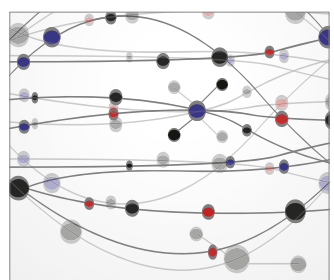

\section{The Scientific} World Journal
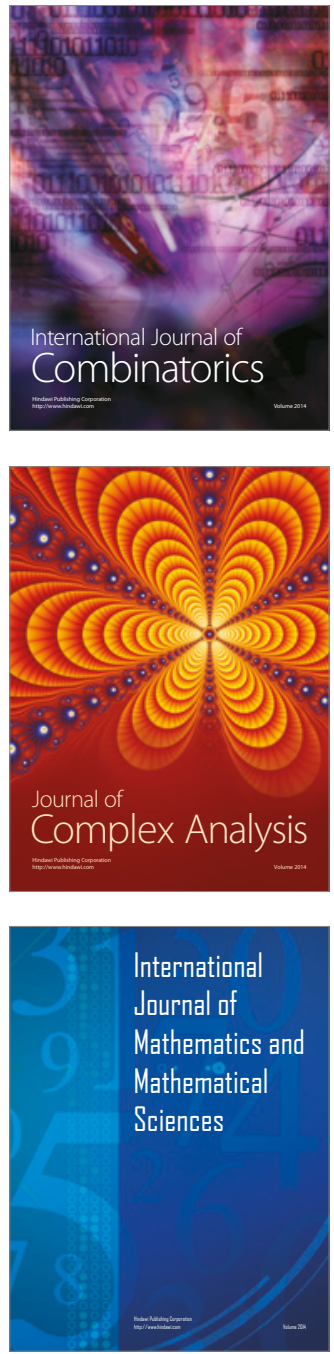
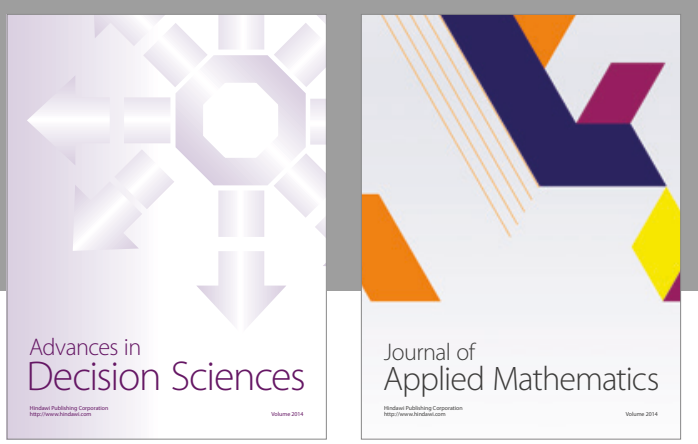

Algebra

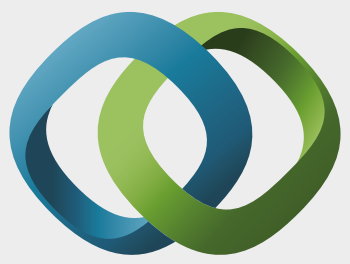

\section{Hindawi}

Submit your manuscripts at

https://www.hindawi.com
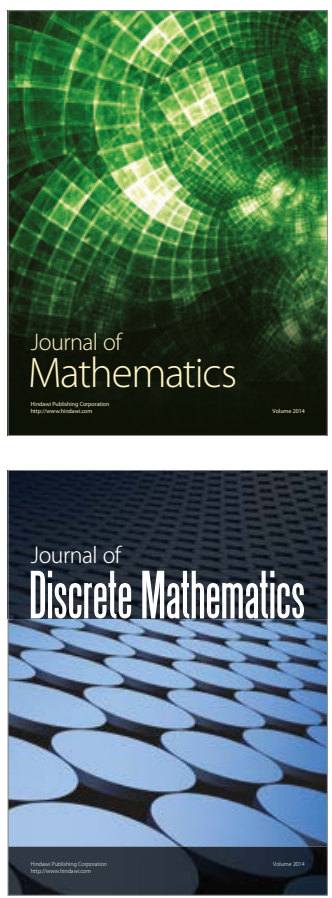

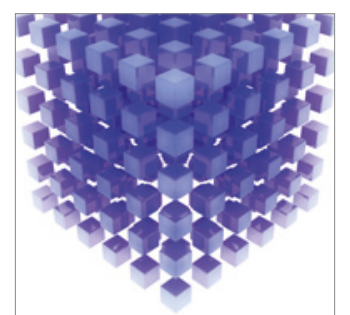

Mathematical Problems in Engineering
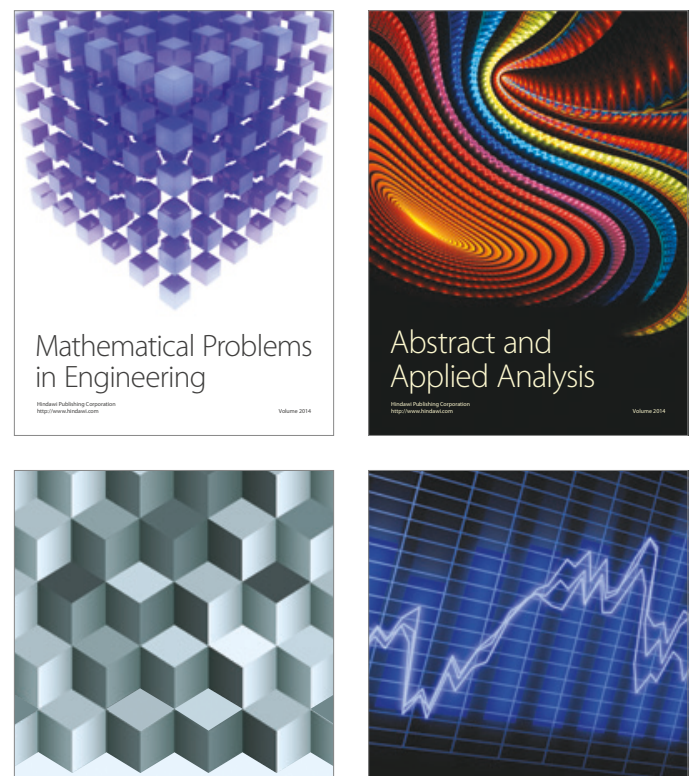

Journal of

Function Spaces

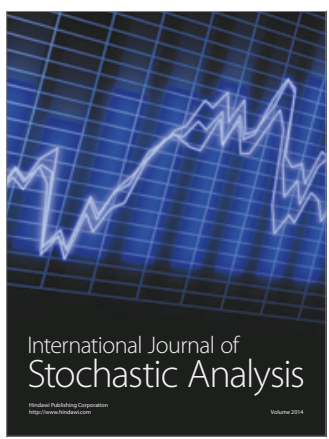

Probability and Statistics
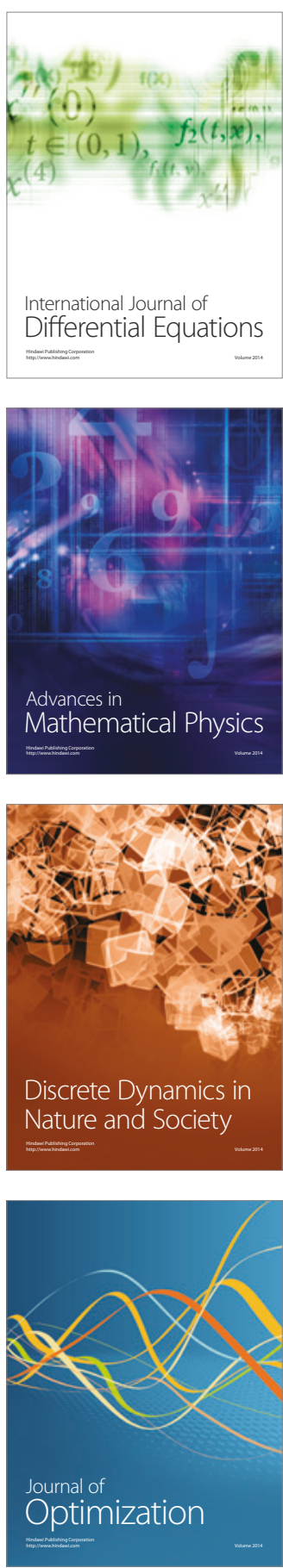